\title{
Numerical Modeling of Oil Pollution in the Eastern Mediterranean Sea
}

\author{
George Zodiatis, Giovanni Coppini, Leonidas Perivoliotis, Robin Lardner, \\ Tiago Alves, Nadia Pinardi, Svitlana Liubartseva, Michela De Dominicis, \\ Evi Bourma, and Antonio Augusto Sepp Neves
}

\begin{abstract}
This chapter presents a summary of major applications in numerical oil spill predictions for the Eastern Mediterranean Sea. Since the trilateral agreement between Cyprus, Egypt, and Israel back in 1997, under the framework of the subregional contingency plan for preparedness and response to major oil spill pollution incidents in the Eastern Mediterranean Sea, several oil spill models have been implemented during real oil pollution accidents and after oil spills that were detected from satellite remote sensing SAR data. In addition, several projects cofinanced by the European Commission addressed particularly issues with oil spill
\end{abstract}

\author{
G. Zodiatis $(\bowtie)$ \\ Oceanography Center, University of Cyprus, Nicosia, Cyprus \\ e-mail: gzodiac@ucy.ac.cy; oceanosgeos@gmail.com \\ G. Coppini and S. Liubartseva \\ Centro Euro-Mediterraneo sui Cambiamenti Climatici, Fondazione, Lecce, Italy \\ e-mail: giovanni.coppini@cmcc.it \\ L. Perivoliotis and E. Bourma \\ Hellenic Centre for Marine Research, Anavissos, Attica, Greece \\ e-mail: lperiv@hcmr.gr; evibourma@hcmr.gr \\ R. Lardner \\ Simon Fraser University, Burnaby, BC, Canada \\ e-mail: lardner@cytanet.com.cy \\ T. Alves \\ 3D Seismic Lab - School of Earth and Ocean Sciences, Cardiff University, Cardiff, UK \\ e-mail: AlvesT@cardiff.ac.uk \\ N. Pinardi and A.A. Sepp Neves \\ Department of Physics and Astronomy, University of Bologna, Bologna, Italy \\ e-mail: nadia.pinardi@unibo.it; antonio.seppneves2@unibo.it \\ M. De Dominicis \\ Marine Systems Modeling Group, National Oceanography Centre, Liverpool, UK \\ e-mail: micdom@noc.ac.uk
}

A. Carpenter and A.G. Kostianoy (eds.), Oil Pollution in the Mediterranean Sea: Part I - The International Context, Hdb Env Chem, DOI 10.1007/698_2017_131,

(C) Springer International Publishing AG 2017 
modeling, taking the advantage of developments in operational oceanography, as well as collaboration with the Mediterranean Oceanographic Network for Global Ocean Observing System (MONGOOS), with the European Maritime Safety Agency CleanSeaNet (EMSA-CSN), and Regional Marine Pollution Emergency Response Centre for the Mediterranean Sea (REMPEC). Major oil pollution incidents in the Eastern Mediterranean and the oil spill modeling applications carried out are summarized in this work. Three well-established operational oil spill modeling systems - two of them characterized by different numerical tools MEDSLIK, MEDSLIK II, and the POSEIDON oil spill models - are described in terms of their applicability to real oil spill pollution events, the Lebanon oil pollution crisis in summer 2006, the case Costa Concordia accident, and the spill event associated with the collision of two cargo vessels in the North Aegean Sea in June 2009. Finally, an overview of the present-day capability of Eastern Mediterranean countries in oil spill modeling is provided in this chapter.

Keywords Eastern Mediterranean Sea, Levantine Basin, MEDSLIK, MEDSLIK II, Oil spill models, POSEIDON OSM

\author{
Contents \\ 1 Introduction \\ 2 Main Oil Pollution Incidents in the Eastern Mediterranean Sea \\ 3 Oil Spill Modeling in the Eastern Mediterranean Sea: A Review \\ 4 The MEDSLIK Oil Spill Modeling System \\ 4.1 The Lebanon Oil Pollution Crisis \\ 5 The POSEIDON Oil Spill Model \\ 5.1 POSEIDON OSM Test Cases \\ 6 MEDSLIK-II: A Community Oil Spill Model for the Mediterranean \\ 6.1 The MEDSLIK II Test Case: The Case of Costa Concordia \\ 7 Oil Spill Risk Mapping \\ 8 Conclusions \\ References
}

\title{
1 Introduction
}

Oil spills in the Eastern Mediterranean Sea, as with any other seas and oceans around the world, can significantly impact the marine environment and are a concern for civil protection authorities and coastal populations in a time of everincreasing shipping volumes and hydrocarbon exploration [1] (Fig. 1). The Eastern Mediterranean Sea finds itself as the locus of one of the busiest shipping corridors in the world [2, 3], with variable weather and sea current patterns depending on seasonality, formation of local storms, and bathymetry. These latter factors have, potentially, a significantly impact on oil slick movement.

The probability of a major oil spill incident to occur in the Eastern Mediterranean Sea is relatively high at present due to increasing exploration and exploitation for hydrocarbons in the Levantine Basin [4] (Fig. 2). This increase in interest from exploration companies was particularly recorded after the discovery of significant 
Numerical Modeling of Oil Pollution in the Eastern Mediterranean Sea

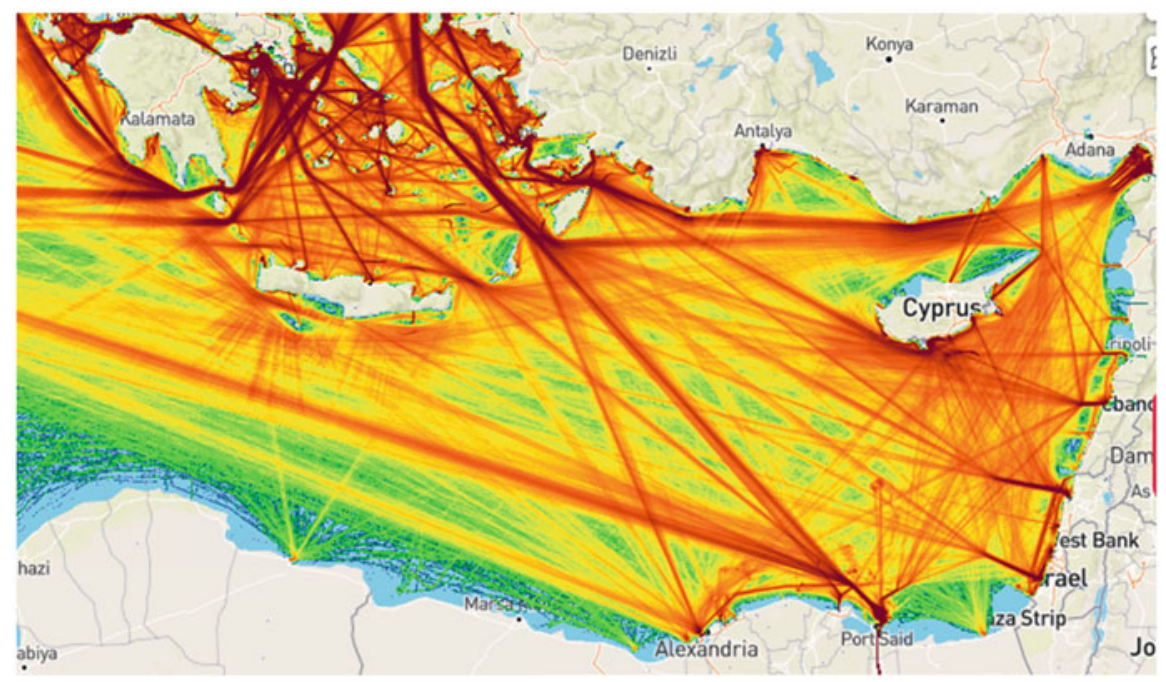

Fig. 1 Marine traffic density in the Eastern Mediterranean Sea (see https://www.marinetraffic.com)

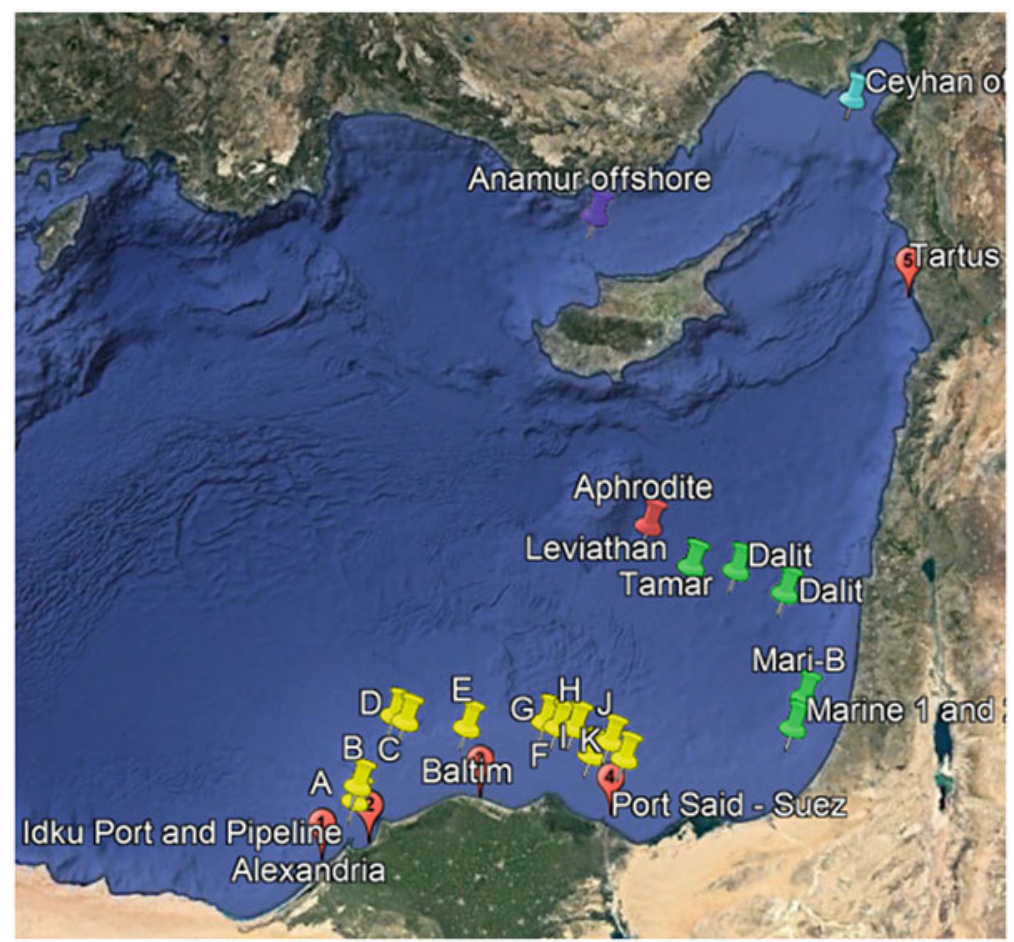

Fig. 2 Major offshore platforms in the Eastern Mediterranean Levantine Basin up to the year 2016 
amounts of oil and gas in the EEZs of Israel, Egypt, and Cyprus. In addition, increase risk of an oil spill accident in the Eastern Mediterranean Sea is associated with:

1. The recent enlargement of the Suez Canal in Egypt, which now accommodates tankers up to 550,000 deadweight (dwt) in volume.

2. Refineries and ports have been upgraded to deal with the expected increase in ship tonnage and volumes of hydrocarbons (both oil and gas) to be produced from new offshore fields.

3. No efficient mitigation plans and real-time surveying technology exist to assist response agencies during major oil spill accidents.

Item (3) comprises a major limitation when considering acute pollution events such as the Lebanon 2006 oil spill, so far the largest oil pollution accident that occurred in the region [5], potential collision accidents along major routes for oil and gas tankers from the Middle East to Europe, from offshore platforms, or pollution accidents resulting from well blowouts in deep waters.

The risks potentially associated with the deployment and operation of offshore installations in the Mediterranean Sea prompted, in 2011, the adoption of a new protocol for the protection of the Mediterranean Sea against pollution from oil/gas exploration and exploitation on the continental shelf and the seabed, known as Offshore Protocol. This is one of the seven protocols of the Barcelona Convention. The Offshore Protocol urges riparian countries to develop Impact Damage Assessments in order to take into account all elements that may affect the sea and the coast during the deployment of offshore drilling installations. The measures to mitigate and to minimize associated drilling risks include the early detection and control of oil spills, the redistribution of available resources for an efficient combat of oil spills at their early stages, proposals for new response mechanisms to fight oil spills, etc. In order to evaluate the consequences of an oil release from planned offshore platforms, national authorities are required to develop an Impact Damage Assessment based on oil spill modeling results. Of crucial importance, in the case of a major oil spill incident, are operational oil spill modeling predictions. These modeled predictions will serve as the initial/forefront tools to assist regional and national contingency plans.

Several initiatives have been developed in the last 5 years to improve the preparedness and response measurements to major oil spill incidents in the Eastern Mediterranean Sea, some of them also addressing oil spill modeling predictions.

The most recent project addressing oil spill predictions in the Mediterranean Sea, using a multi-model approach, was the Mediterranean Decision Support System for Marine Safety (MEDESS-4MS) (http://www.medess4ms.eu/) funded by the European Commission (EC) throughout the MED Program. Moreover, to address the access of marine data, the European Commission has established the European Marine Observation and Data Network (EMODnet), which now provides a single entry point for accessing and retrieving marine data derived from the EMODnet thematic portals, from the Copernicus Marine Environment Monitoring Service $(C M E M S)$, and from other initiatives existing at more regional "basin" 
scales. In order to test and evaluate how comprehensive and accurate are the monitoring and forecasting marine data available through the EMODnet and Copernicus thematic portals (http://www.emodnet-mediterranean.eu/), at the scale of the Mediterranean Sea, 11 challenges were defined where the marine data can benefit key downstream applications to foster BlueMed economies.

One of the EMODnet Mediterranean Checkpoint challenges comprises the oil platform leaks, which aims at providing oil spill predictions so that one can determine the likely trajectory of oil slicks and the statistical likelihood that sensitive coastal habitats, species, or tourist beaches will be affected. The oil platform leak challenge handles the ability to produce oil spill predictions in the Mediterranean Sea, where the EC generates the oil leak alert online. In the framework of this challenge, oil spill predictions can be connected to existing oil spill monitoring platforms (EMSA-CSN and REMPEC) using the well-established oil spill models MEDSLIK and MEDSLIK II and environmental data from CMEMS, ECMWF, or other met-ocean forecasting systems such as CYCOFOS, POSEIDON, SKIRON, and ALERMO [6-10].

Extensive industrial activities related to shipping and hydrocarbon industry in the Mediterranean Sea, particularly in its eastern region, show the necessity for having in place a reliable, well-tested oil spill modeling system to help response agencies in mitigating any accident. European (EMSA-CSN), regional (REMPEC), and national response agencies, civil protection teams, academia, and industrial and NGO stakeholders have been working in tandem to develop, improve, and operate oil spill models for predicting real and/or potential oil spills, at surface or in the subsurface, forward and backward [4, 5, 11-13]. They have recognized a strong influence of variable oceanographic and weather conditions on the movement of oil in the entire Eastern Mediterranean Sea and have demonstrated a close effect of seafloor bathymetry on regional currents $[4,14]$. After modeling real and hypothetical oil spills in key hydrocarbon exploration areas, and shipping lanes in the Eastern Mediterranean Levantine region, [4, 14-16] confirmed that the variability of weather and oceanographic conditions has a crucial effect on oil slick movement (advection) and oil spill characteristics (weathering processes) through time and space.

The general circulation pattern in the Eastern Mediterranean Levantine region is anticlockwise, with several cyclonic and anticyclonic gyres, respectively, the Rhodos gyre and the Mersa Matruh, and mesoscale features such as the Cyprus and Shikmona warm core eddies. Flow jets also occur in the area such as the MMJ transferring the Modified Atlantic Waters offshore across the Levantine region and the Asia Minor Current. This latter current is capable of transferring, along the southern coast of Turkey, the warm and saline waters of the easternmost part of the Levantine Basin further to the north along the eastern Aegean Sea, after passing the eastern Cretan Arc Straits [17-19].

The Eastern Mediterranean Sea is known to be the largest subregion of the Mediterranean and is subdivided geographically as several distinct basins: (a) Aegean Sea, (b) Levantine Basin, (c) Cretan Passage, and (d) the Ionian Sea. The Eastern Mediterranean is chiefly a deep basin with exception of the shallow 
coastal zones of Egypt and Libya. The Eastern Mediterranean Sea is connected to the Black Sea to the north by the Strait of Dardanelles and Bosporus, to the Red Sea to the southeast via the recently (2016) enlarged Suez Canal, and to the Western Mediterranean to the west through the Ionian Sea and the Sicilian Channel (Fig. 3). These sea passages constitute the main shipping corridors on the Eastern Mediterranean Sea, while on the SE part of the Levantine Basin, on the shallow continental shelf of Egypt as well as offshore the EEZ of Israel and Cyprus, an increase of hydrocarbon exploration has been observed for the last decade.

Technological advances provided by geo-information systems, such as the use of satellite synthetic aperture radar (SAR) and automatic identification system (AIS), made possible the detection of oil slicks and of the sources responsible for oil leakages on the sea (Fig. 4). At present, the coupling of satellite remote sensing systems with oil spill models constitutes an effective monitoring and forecasting tool (Fig. 5) used to discourage illegal operational oil discharges [20-24]. From SAR images collected during the period spanning 1999-2004, up to 2,544 possible oil spills were detected in the Eastern Mediterranean [25]. Similarly, in the NE part of the Eastern Mediterranean Levantine region, more than 1,200 possible oil spills were detected from 2007 to 2011 [11]. The majority of SAR-detected oil slicks followed the main shipping routes in the Levantine region and were the result of routine operations such as degassing, deballasting, and other actions involving illegal discharges of oil, in violation of the EU Directive 2005/35 (Fig. 4).

A common practice for assisting the national and regional contingency plans is to have in place (together with monitoring systems) dedicated tools providing

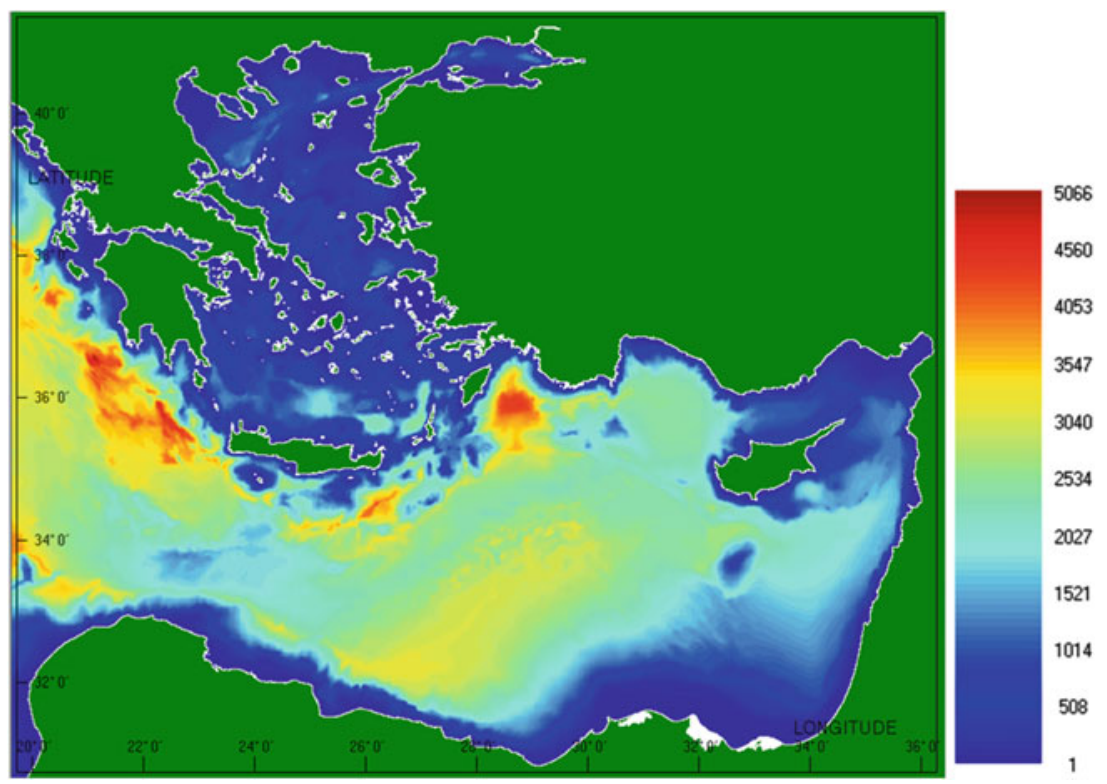

Fig. 3 Geometry and bathymetry of the Eastern Mediterranean Sea 


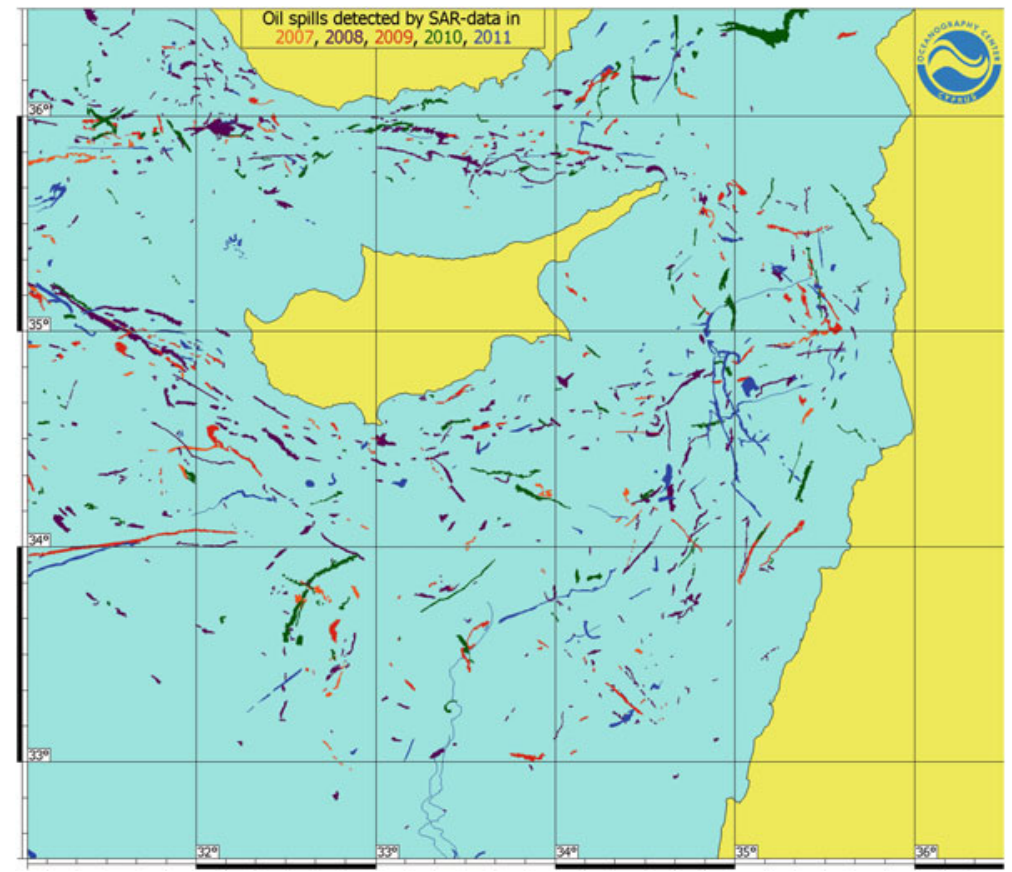

Fig. 4 Possible oil spills detected in the NE Levantine region during the period spanning 2007-2011 (map from Zodiatis et al. [11])
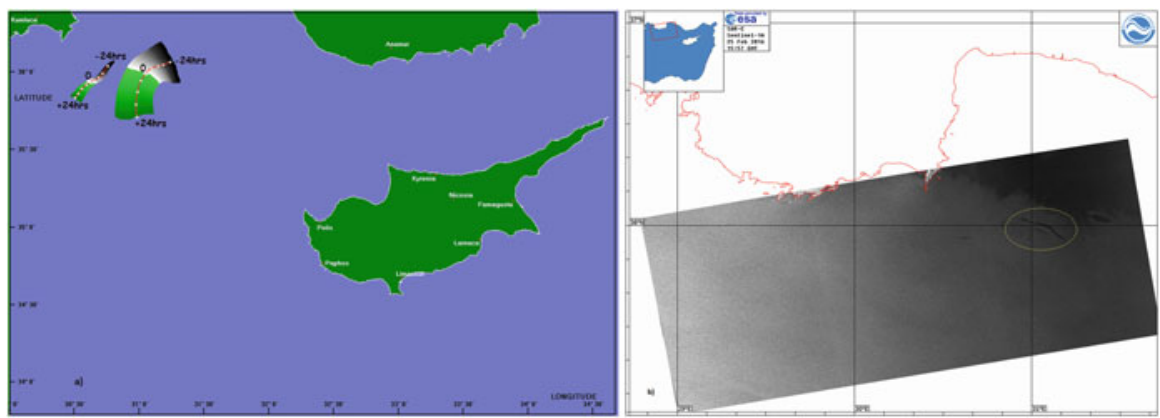

Fig. 5 Example of the detection of oil slicks using ESA Sentinel SAR data and MEDSLIK 24 hour forward and backtracking predictions (date: 25/2/2016). White, initial oil slick position, $0 \mathrm{~h}$ (date/time of observation); dark green, forecast $+24 \mathrm{~h}$; black, backtracking $-24 \mathrm{~h}$

operationally, on a routine basis, high-resolution met-ocean information of the main parameters (sea currents, winds, waves, sea surface temperature, sea water density) affecting the advection and the weathering of the oil spills [11]. The use of this 
information by oil spill models provides the capability for operational forecasting or hindcast predictions of oil spill advection and weathering (Fig. 5), allowing the agencies in charge to combat oil pollution and the decision-makers to promptly respond to oil pollution crises.

For the last two decades, developments in operational oceanography in Europe made possible for the EC to implement the CMEMS in 2015, which provides daily, reliable, and quality-controlled met-ocean forecasts for the European seas, including the Mediterranean Sea [26]. In the Eastern Mediterranean Sea, several subregional met-ocean forecasting systems exist at present; a total of 28 systems downscale the CMEMS regional data to provide high-resolution forecasting and hindcast data for the needs of the oil spill predictions [27]. In order to harmonize the different met-ocean forecasting in terms of oil spill prediction modeling, the EC funded the MEDESS-4MS project to make possible the use of common parameters and formats for input/output data. These data are needed for well-established oil spill models in the region, including those operated in the Eastern Mediterranean Sea: MEDSLIK, POSEIDON OSM, and MEDSLIK II.

The chapter is organized as follows: in Sect. 2 the main oil pollution incidents in the Eastern Mediterranean are briefly reported; in Sect. 3 an overview of major research projects focused on oil spill modeling in the Eastern Mediterranean is summarized; in Sects. 4-6, the three well-established oil spill modeling systems implemented in the Eastern Mediterranean Sea are described: (a) MEDSLIK, (b) POSEIDON OSM, and (c) MEDSLIK II. Their application during real oil spill incidents is briefly explained. At Sect. 7 risk mapping for the Lebanon oil spill crisis in summer 2006 is presented based on the international standard ISO 31000:2009. Finally, concluding remarks are included in Sect. 8.

\section{Main Oil Pollution Incidents in the Eastern Mediterranean Sea}

Several major oil spill incidents were reported in the Eastern Mediterranean Sea in the past four decades. A brief description of these pollution incidents is documented in the ITOPF (International Tanker Owners Pollution Federation; www.itopf.com) and also in [4] for the wider area of the Levant Basin. The largest oil spill accidents include:

1. The grounding of the Messiniaki Frontis (1979) in South Crete. In this accident, a cargo ship was grounded off southern Crete spilling 7,000 tons of crude. Much of the spilled oil dispersed at sea although a limited amount of shoreline cleanup was required.

2. The sinking of the Irenes Serenade (1980) in the Pylos Harbor, Peloponnese. This accident was confined to the harbor and was followed by another accident in 1993. 
3. The grounding of the Iliad (1993) at the same Pylos Harbor, Greece. In this case, cleaning operation was facilitated by mechanical recovery and shoreline cleanup by a private contractor.

4. The collision of the Geroi Cernomorya (1992), in which 8,000 tons of crude oil was spilt. In this accident, the abovementioned vessel spilled crude oil into the Aegean Sea following a collision. Most of the oil dispersed naturally, but parts of Mykonos Island were lightly oiled. A contractor undertook the cleanup supervised by the port authority.

5. The collision of La Guardia (1994) with pipeline systems of a refinery near Athens. In this accident, supply pipes spilt 400 tons of heavy crude while the vessel was maneuvering out of dock at the Aspropyrgos Hellenic Refinery.

6. The spillage of 300 tons of Arabian light crude oil by the Kriti Sea (1996), offshore Isthmia. The vessel was loading at the Motor Oil Refinery Installations at Agioi Theodoroi Port.

7. The explosion of the tanker Slops (2000) in the Port of Piraeus, near Athens, while anchored. An unknown but substantial quantity of oil was spilled, some of which burned in the ensuing fire.

8. The spillage of 500 tons of bunker fuel (oil and diesel) in Lefkandi, Central Greece, by the $M / V$ Eurobulker $X$ (2000).

9. The Lebanon oil pollution crisis in summer of 2006, which is considered the biggest so far oil pollution in the Eastern Mediterranean Sea, for more details see Sect. 4.1.

10. The 2013 "Gastria oil spill incident" in the northern part of the Famagusta Bay, at the east coastal zone of Cyprus, outlined below:

An oil spill, approximately 100 tons of heavy fuel oil (HFO), occurred caused by a Turkish tanker at 0.67 nautical miles from the shore (at the reported location of 3518.61 N-03359.50 E) on 16 July 2013 at 10:00 UTC, while offloaded HFO to an oil terminal for the needs of the nearby "Kalecik" power station, owned and operated by the Turkish "Aksa" energy company in the Turkey, occupied part of Cyprus. $^{1}$

The oil spill was also identified by SAR images provided by EMSA-CSN portal. Within the frame of the Cyprus National Contingency Plan, the MEDSLIK oil spill model provided the predictions of the slick and has shown that due to the very-very weak winds and of the sea currents, the spill needed around $18 \mathrm{~h}$ to arrive at the nearby coast. Unfortunately, due to the political situation between Turkey and Cyprus, the Turkish forces denied the offered support and equipment from the Cyprus response agencies to combat the spill while it was at sea. This resulted the beaching of the majority of oil in a relative extended part of the northern shore of the bay. Later on, with the increase of winds and the action of waves, certain amount of the percentage of oil at coast but potentially releasable reentered the sea

\footnotetext{
${ }^{1}$ See http://www.reuters.com/article/cyprus-spill-idUSL6N0FN1Z320130717 and http://www. hurriyetdailynews.com/40-tons-oil-spilled-into-sea-turkish-firm-admits.aspx?pageID=238\&nID $=50910 \&$ NewsCatID $=348$.
} 
as small slick parcels, scattered by the currents in the southern part of the bay, both simulated by MEDSLIK and verified by in situ observations.

\section{Oil Spill Modeling in the Eastern Mediterranean Sea: A Review}

Several initiatives have been carried out in the last decade to improve the preparedness and response measurements to major oil spill incidents in the Eastern Mediterranean Sea. One of these initiatives concerns oil spill predictions.

The major project addressing the issue of oil spill modeling prediction in the region is the Mediterranean Decision Support System for Marine Safety MEDESS$4 \mathrm{MS}^{2}$ (funded by the EC throughout the MED Program). The MEDESS-4MS project is dedicated to the prevention of maritime risks and subsequent strengthening of maritime safety related to oil spill pollution in the Mediterranean Sea. MEDESS-4MS delivered an integrated operational multi-model oil spill prediction service for the Mediterranean Sea [27], connected to existing monitoring platforms (REMPEC, EMSA-CSN, AIS), using well-established oil spill modeling systems, data from the Copernicus Marine Environment Monitoring Service (CMEMS), and national ocean forecasting systems. MEDESS-4MS constitutes a successful joint project between the members of the Mediterranean Oceanographic Network for Global Ocean Observing Systems (MONGOOS) and of several response agencies including REMPEC. MEDESS-4MS uses information on position of the oil slick, links it to four well-established oil spill models in the Mediterranean Sea capable of predicting the movement pollutant, thus providing tailored products to oil spill crisis management users. This workflow contributes substantially to the prevention of maritime risks and to maritime safety.

One of the major goals of MEDES4MS is the improvement of the modeling tools used among different institutional and operational partners, in order to provide an integrated approach to maritime safety, particularly to support the response against oil spill pollution in the Mediterranean Sea. This objective was achieved through interconnecting the different parts of MEDESS-4MS oil spill monitoring and forecasting services with the network data repository (NDR) and user interfaces (UI) [27].

During MEDESS-4MS, four well-established stand-alone oil spill systems (MEDSLIK, MEDSLIK-II, POSEIDON-OSM, MOTHY) in use in the Mediterranean Sea were interconnected into an integrated multi-model oil spill forecasting network. In order to accomplish this same integrative step, each stand-alone system underwent changes for the implementation of a common data exchange system providing the link between the necessary information that should be available to the oil spill systems, environmental data from the CMEMS, the national ocean

${ }^{2}$ See www.medess4ms.eu/. 
forecasting systems, the oil slick data from existing monitoring platforms (REMPEC, EMSA CSN), and the data from supplementary resources such as ESA and AIS.

The main steps toward the implementation of the MEDESS-4MS multi-model oil spill forecasting system were the understanding of existing oil spill forecasting systems, the design of common specifications for the data exchange and interfacing with oil spill data from existing monitoring systems, the implementation of common standards to all MEDESS-4MS modeling system modules, and, finally, the testing of the overall system performance in operational mode.

The Risk Assessment of Offshore Platforms in the Eastern Mediterranean (RAOP-MED) project, funded by the EC, provided a holistic study on the risks associated with exploration and production of hydrocarbon in the Eastern Mediterranean Sea. This included the prevention, early detection of oil spills, and reorganization and redistribution of resources available for an efficient combat of oil spills at their early stages. In order to evaluate the consequences of a release of oil from offshore platforms in the Eastern Mediterranean Sea, Impact Damage Assessment studies were carried out under the framework of the RAOP-MED project. To this extent, the Impact Damage Assessment studies are based on the predictions of the well-established MEDSLIK oil spill model, using downscaled CMEMS MED MFC and CYCOFOS data, as well as wind data provided by SKIRON.

Under the framework of RAOP-MED, long-term oil spill hindcast simulations were carried out for the first time to study weekly, seasonal, and interannual variability in oil spill predictions for the Levantine Basin, using met-ocean data of high spatial and temporal resolution. The hindcast oil spill simulations were initially carried out for 10 planned drilling locations at the southeast EEZ of Cyprus by ENI [14] and also for 19 existing offshore wells located in the Levantine Basin, where hydrocarbon exploration and production are ongoing [4].

The oil spill modeling scenarios for the 10 planned drill sites and for the 19 existing platforms were prepared for week to week conditions for a period of 4 years (2010-2014), presenting the detailed trajectories of hypothetical oil spills. These trajectories were computed together with graphs corresponding to the percentage volumes of dispersed, evaporated, trapped at the surface, first impact at coast, extend of the affected coastline, extend of the sea area affected 1-20 days after the onset of the spill. The modeled spills took into account the release of $55,800 \mathrm{bbls}^{3}$ of medium-grade Belayim oil, the common type produced in the Levantine Basin, following the REMPEC MEDEXPOL 2013 exercise [28].

The long-term hindcast oil spill modeling for existing offshore platforms suggests that the most vulnerable areas are those in the eastern part of the Levantine Basin - offshore and coastal Israel, Lebanon, and the Egyptian coastline. The early deployment of response measures, following the established response protocols for large oil spill accidents from offshore platforms, will minimize the impact of any future pollution accidents on the coastal zones. Due to the significant

\footnotetext{
${ }^{3}$ The standard volume unit for crude oil measurement, the 42-gal barrel ("bbl").
} 
environmental, social, and economic impacts that oil spills may impose on the Levantine Basin, continuous improvements in the prevention and response capabilities are necessary for the region. This can be achieved by investing in monitoring assets, in situ and remote sensing, in technological innovation and operational oil spill, and in ocean forecasting models.

At present, several institutions and agencies throughout the Eastern Mediterranean Sea, in EC member and nonmember States, implement and operate oil spill models in operational and hindcast modes using downscaled CMEMS met-ocean data, following the developments in EC projects regarding the operational oceanography and the oil spill modeling $[15,27]$. Most of downscaled and downstream applications are capable to provide oil spill predictions only at their national exclusive economic zones (EEZ), whereas in the framework of the MEDESS-MS project, the well-established oil spill models (MEDSLIK, MEDSLIK-II, POSEIDON OSM) are applicable to the entire Eastern Mediterranean Sea using any available met-ocean information from the 28 different harmonized regional, subregional, and coastal downscaled met-ocean systems of different resolutions and different surface forcing(s).

\section{The MEDSLIK Oil Spill Modeling System}

MEDSLIK is a well-established 3D oil spill model that predicts the transport, fate, and weathering of oil spills $[11,13]$. It is used by several response agencies and institutions around the Mediterranean Sea.

MEDSLIK was successfully used during the Lebanon oil spill pollution crisis, in summer 2006, considered so far to be the biggest oil spill pollution incident in the Eastern Mediterranean Sea [5, 29].

MEDSLIK has been used operationally for real oil spill accidents and for preparedness in contingency planning within the framework of pilot projects with the Regional Marine Pollution Emergency Response Centre for the Mediterranean Sea (REMPEC) and the European Maritime Safety Agency CleanSeaNet (EMSACSN). It was also used in the EC project NEREIDs supported by the European Civil Protection Agency. ${ }^{4}$

The MEDSLIK oil spill model is used by the Cyprus National Contingency Plan and has been used also in the framework of the subregional contingency plan in preparedness and response to major oil spill incidents in the Eastern Mediterranean Levantine Basin between the Republic of Cyprus, the State of Israel, and the Arab Republic of Egypt, a EC project coordinated by REMPEC.

Moreover, the MEDSLIK oil spill model has been used in the framework of dedicated EC-funded projects, for example, the MERSEA-Strand1, MERSEA-IP, MyOcean, MyOcean-2, and MyOcean-FO, promoting the development of the EC

\footnotetext{
${ }^{4}$ See www.nereids.eu.
} 


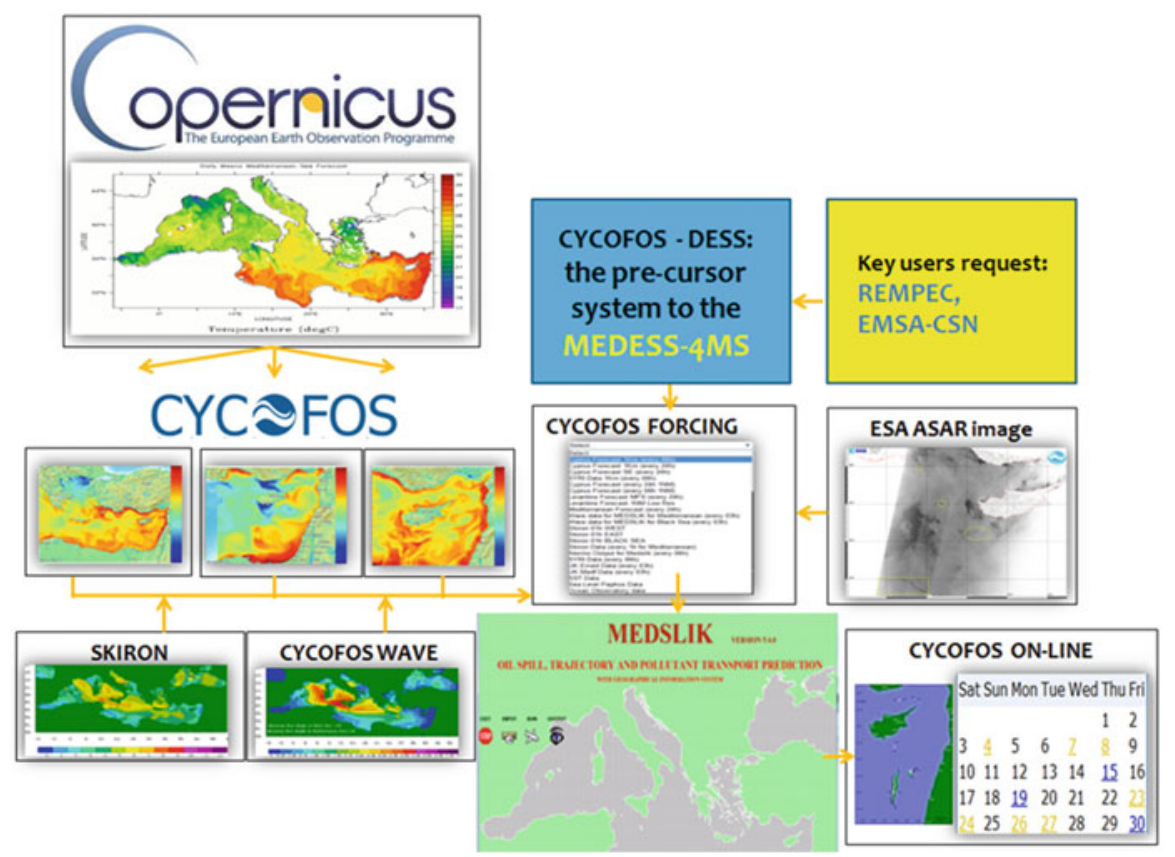

Fig. 6 The MEDSLIK oil spill model uses regional CMEMS MED MFC and the downscaled CYCOFOS met-ocean data and can incorporate emergency warnings from the Mediterranean and European response agencies such as REMPEC and EMSA-CSN. The MEDSLIK oil spill prediction system was used as the precursor service to build the MEDESS-4MS multi-model oil spill prediction service for the entire Mediterranean Sea

CMEMS (Copernicus Marine Environment Monitoring Service), formerly known as the Global Monitoring for Environment and Security (GMES).

The MEDSLIK oil spill model has been implemented in many other EC-funded projects regarding oil spill predictions using the operational ocean forecasts, for example, the MFSTEP, ECOOP, EMODnet Mediterranean Checkpoint, RAOPMED, and the MEDESS-4MS. At present, MEDSLIK is coupled with CMEMS MED MFC, CYCOFOS, ECMWF, and SKIRON forcing data using the input/ output "standards" set in the frame of MEDESS-4MS project (Fig. 6).

The MEDSLIK oil spill model incorporates oil slick at sea surface; evaporation, emulsification, dispersion in water column, adhesion to coast, sedimentation at shallow waters, viscosity changes, oil density, oil thickness, oil slick volume, and the length of the impacted coast are also derived. The oil spill movement is simulated using a Monte Carlo ${ }^{5}$ approach. The pollutant is divided into a large number of Lagrangian parcels of equal size. At each time step, each parcel is given

\footnotetext{
${ }^{5}$ Is a broad class of computational algorithms that rely on random sampling to obtain numerical results that might be deterministic in principle.
} 
a convective and a diffusive displacement. In detail, the oil is considered to have a light evaporative component and a heavy non-evaporative component. Emulsification is also simulated, and the viscosity changes of the oil are computed according to the amount of emulsification and evaporation of the oil. The model simulates slick transport taking into account that the movement of the surface slick is governed by currents, waves (Stokes drift ${ }^{6}$ ), and wind, while the diffusion of the slick is simulated by a random walk (Monte Carlo) model. The oil may be dispersed into the water column by wave action, while the dispersed oil is moved by currents only. Mechanical spreading of the initial slick is also included. The number of parcels used by the MEDSLIK model to form the oil spill may range from 10,000 up to 500,000 , while the water column structure is described by 15 vertical layers which are adjusted to the relevant hydrodynamic/oceanographic forecasts provided with CMEMS, CYCOFOS, or any adapted MEDESS-4MS predictive models.

The MEDSLIK oil spill model prediction length may vary from few hours up to 3 weeks, but by using the "restart" facility of the model oil spill prediction length, it can be extended further depending on the end-user application requirements and the forcing availability.

The operational implementation of the MEDSLIK oil spill model consists of the following modules:

- The setup module for the model domain and required parameters

- The visual interface for input of the spill data

- The run module that performs the simulation

- The visual interface for viewing the output

In parallel, the MEDSLIK oil spill model contains the following features:

- The inclusion of built-in database with 240 different oil types characteristics, provided by REMPEC.

- The switching from coarse- to high-resolution ocean forecasting data when the oil slick passes from a coarse- to a higher-resolution domain.

- The model allows assimilation of oil slick observations, from in situ or aerial, to correct any predictions if needed.

- The effect of deployment of oil booms and/or oil skimmers/dispersants can be examined in order to assist any response measures.

- Continuous or instantaneous oil spills moving or from drifting ships, whose slicks merge, can be modeled together.

- Multiple oil spill predictions can be provided for different locations.

- Backward-backtracking simulations for tracking the source of oil spill pollution.

- The integration with AIS data, upon the availability of this same type of data.

- The simulation of subsurface oil spills at any given water depth, implementing an improved new plume model (Fig. 7).

\footnotetext{
${ }^{6}$ Is the average velocity of a particle floating at the free sea surface in the direction of wave propagation.
} 


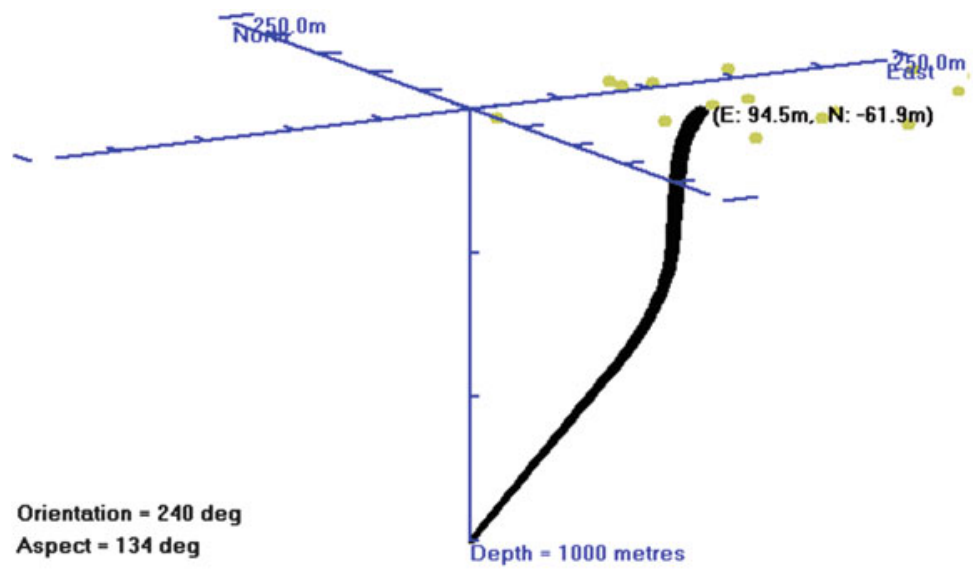

Plume displacement $=94.5 \mathrm{~m}$ East $-61.9 \mathrm{~m}$ North

Fig. 7 An example of the horizontal displacement $(m)$ of the oil plume from the MEDSLIK improved oil plume model, with the source of oil leakage at 1,000 m depth

- The coupling with SAR satellite data, any shape of the slick images from EMSA-CSN, as well as with the ESA data (previously from ENVISAT, nowadays from SENTINEL) for forward- and backward-backtracking predictions.

- Includes a simple GIS to allow information on resources.

The MEDESS-4MS standard input/output oil spill prediction format files [27] have been integrated into the MEDSLIK model, where the met-ocean data are in NetCDF files (network Common Data Form). The required atmospheric forcing for the model integration consists of the wind speed and direction. The significant wave height and the wave period are also required to estimate the Strokes drift while the hydrodynamic/oceanographic forcing is defined by the U,V current components at 15 vertical levels, together with the sea surface temperature. Bathymetric data are also required for the model integration.

MEDSLIK was extensively used for the Lebanon oil pollution crisis in the summer 2006 [5, 29]. Similarly, MEDSLIK was used for a smaller oil pollution incident during summer 2013 near the northeastern coastal area of Cyprus. In addition, MEDSLIK is used for operational $24 \mathrm{~h}$ forward- and backwardbacktracking of oil slick identified by SAR images, either from EMSA CSN dedicated portal or from ESA images. Spanning the period between 2007 and 2012, more than 1,200 possible oil slicks were identified, and oil slick simulations ( $24 \mathrm{~h}$ forward and backward) were carried out with MEDSLIK for each one of these possible oil slicks [11].

Several drifter experiments took place in 2007 in the Eastern Mediterranean Sea to assess the accuracy of the drift component of the MEDSLIK model [30]. The evaluation lasted for more than a month, using various surface drifters (Fig. 8). 


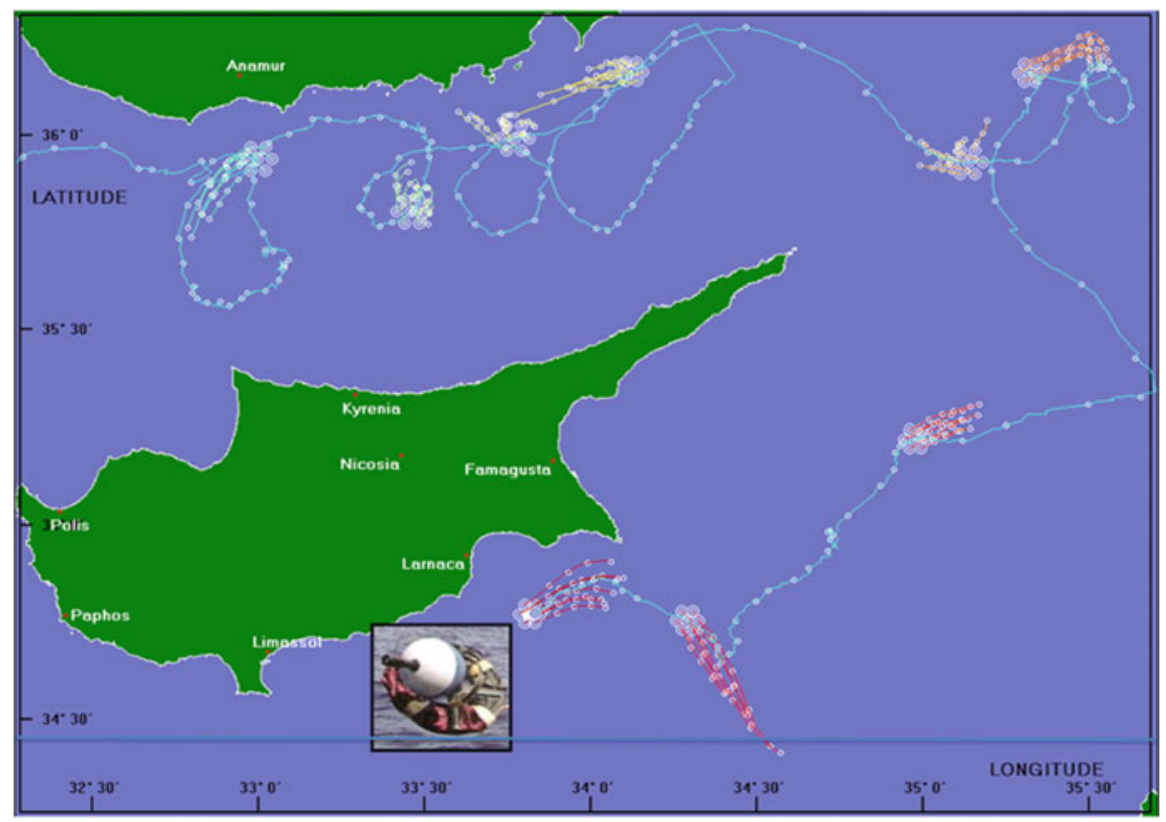

Fig. 8 Example of integrated comparisons between the MEDSLIK multiple virtual floating objects trajectory $24 \mathrm{~h}$ predictions and the trajectory of an SVP drifter from February to March 2007, during the ECOOP project. The CYCOFOS and SKIRON forcing data were used in the MEDSLIK models (map after Zodiatis et al. [30])

\subsection{The Lebanon Oil Pollution Crisis}

A large oil spill occurred in mid-July 2006 at the Jiyeh power plant, located $30 \mathrm{~km}$ south of Beirut, Lebanon. The amount of oil spilt was reported as between 15,000 and 20,000 tons, and the type of oil is heavy fuel with an API of about 20. The spill took the form of a continuous leakage of oil from the power plant, starting at 08:00 h on 13 July 2006 [5, 29]. The operational current forecast for mid-July 2006 from the CYCOFOS-Cyprus Coastal Ocean Observing and Forecasting System, which has a resolution of $1 \mathrm{~km}$, showed a northerly flow parallel to and close to the coasts of Lebanon and Syria. Flow velocities were in the range of $20-30 \mathrm{~cm} / \mathrm{s}$. It turned out that these features persisted for the next 2 months, apart from the occasional development of eddies behind various headlands. The SKIRON wind forecast showed winds in the vicinity of the spill that varied in direction between southwest and south. This same wind pattern remained steady for most of the ensuing 2 months, with the wind strength varying generally between 2 and $7 \mathrm{~m} / \mathrm{s}$.

The oil spill predictions extracted from the MEDSLIK model were consistent with satellite observations (SAR and MODIS): the oil moved northward by the currents and winds, while very large amounts were deposited on the coast adjacent to the Jiyeh power plant and between there and South Beirut. Some of these coastal deposits were subsequently washed back into the water and moved northward. To 
the north of Beirut, MEDSLIK predicted a significant coastal impact between Beirut and Chekka and both north and south of Tartus, with a relatively smaller coastal impact almost as far north as Latakia (Figs. 9 and 10). These predictions are borne out by the satellite images.

Within 3 days of the start of the incident, due to the high sea surface temperature and moderately strong winds, evaporation of the oil was virtually completed with about $20 \%$ of the oil evaporated.

The position of the oil slick after 5 days was predicted by MEDSLIK oil spill model. A large fraction of the oil was driven onto the coast in the immediate neighborhood of the power plant, while some has rounded the headland of South Beirut and had extended to the north of Chekka.

Very heavy concentrations of oil were predicted by MEDSLIK on the coast near the Jiyeh power plant and on the promontory of South Beirut. Moderate concentrations were predicted for the coast between Beirut and Chekka, and extending up to Tartus with some impact almost as far north as Latakia. No oil was predicted north of Latakia. These predictions are consistent with MODIS and SAR images as well as with observation from a United Nations' monitoring mission (Fig. 11).

\section{The POSEIDON Oil Spill Model}

The POSEIDON OSM is an oil spill model developed by the Hellenic Centre for Marine Research (HCMR) as a standard module of the POSEIDON Operational Oceanography System, implemented and operating in the Greek Seas since 2000. The POSEIDON OSM has been efficiently used in the framework of several European-funded projects concerning the prevention, contingency planning, and preparedness during real oil spill accidents. These projects have been supported by European environmental agencies such as the Regional Marine Pollution Emergency Response Centre for the Mediterranean Sea (REMPEC) and the European Maritime Safety Agency (EMSA).

The POSEIDON OSM has also been used operationally, providing support to the Greek marine authorities during real accidents in 2009, in the North Aegean Sea [31], and also detection services through SAR image analyses. The system has also been used as a forecasting service for the effective management of oil spill incidents in the Greek Seas (ESA funded projects: ROSES, MARCOAST). The POSEIDON OSM has been recently integrated as a standard module of the multi-model Mediterranean Forecasting System implemented during the MEDESS-4MS project [27].

After its first implementation into the POSEIDON system [32], the POSEIDON OSM was further developed and upgraded during several research projects. A major upgrade of the system was completed during the research projects ROSES (Real Time Ocean Services for Environment and Security, 2003-2004) and MARCOAST (Marine and Coastal Environmental Information Services, 2005-2008), funded by the European Space Agency (ESA). These two projects 


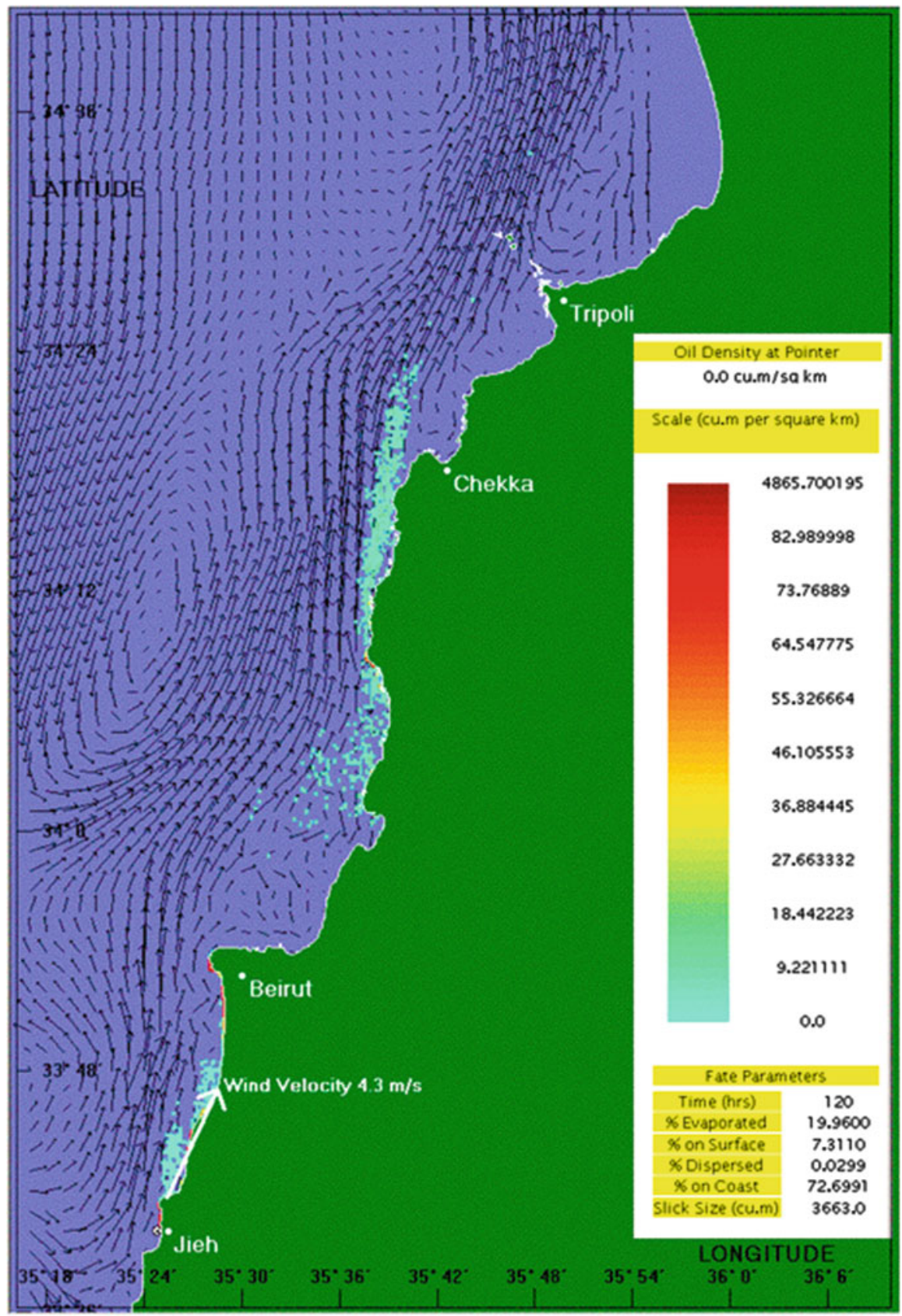

Fig. 9 MEDSLIK predictions for the oil slick 5 days after the onset of the spill (after Lardner et al. [29]) 
Numerical Modeling of Oil Pollution in the Eastern Mediterranean Sea

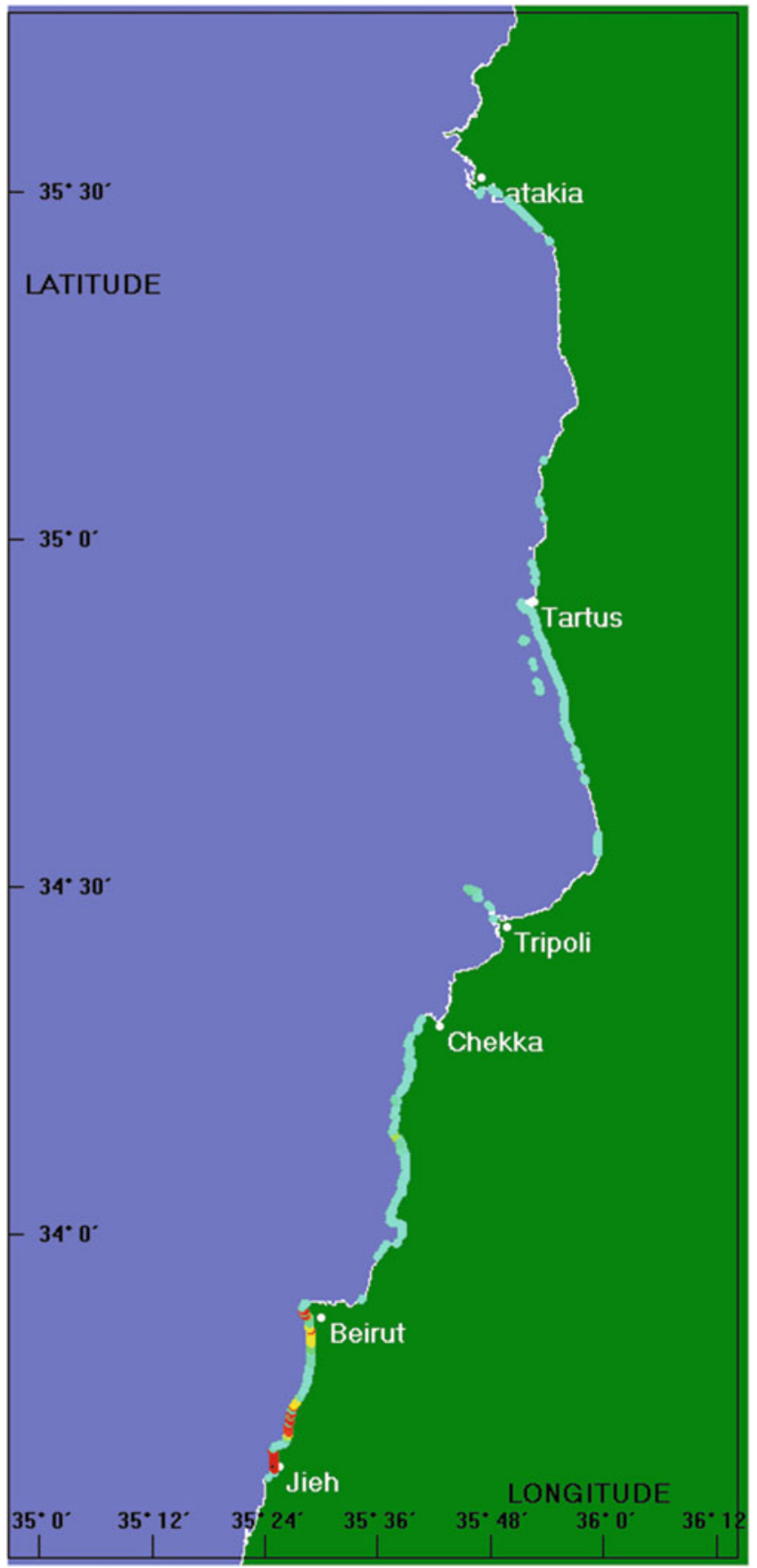

Fig. 10 MEDSLIK predictions of coastal impact 30 days after the onset of the Lebanon spill (after Lardner et al. [29]) 
G. Zodiatis et al.

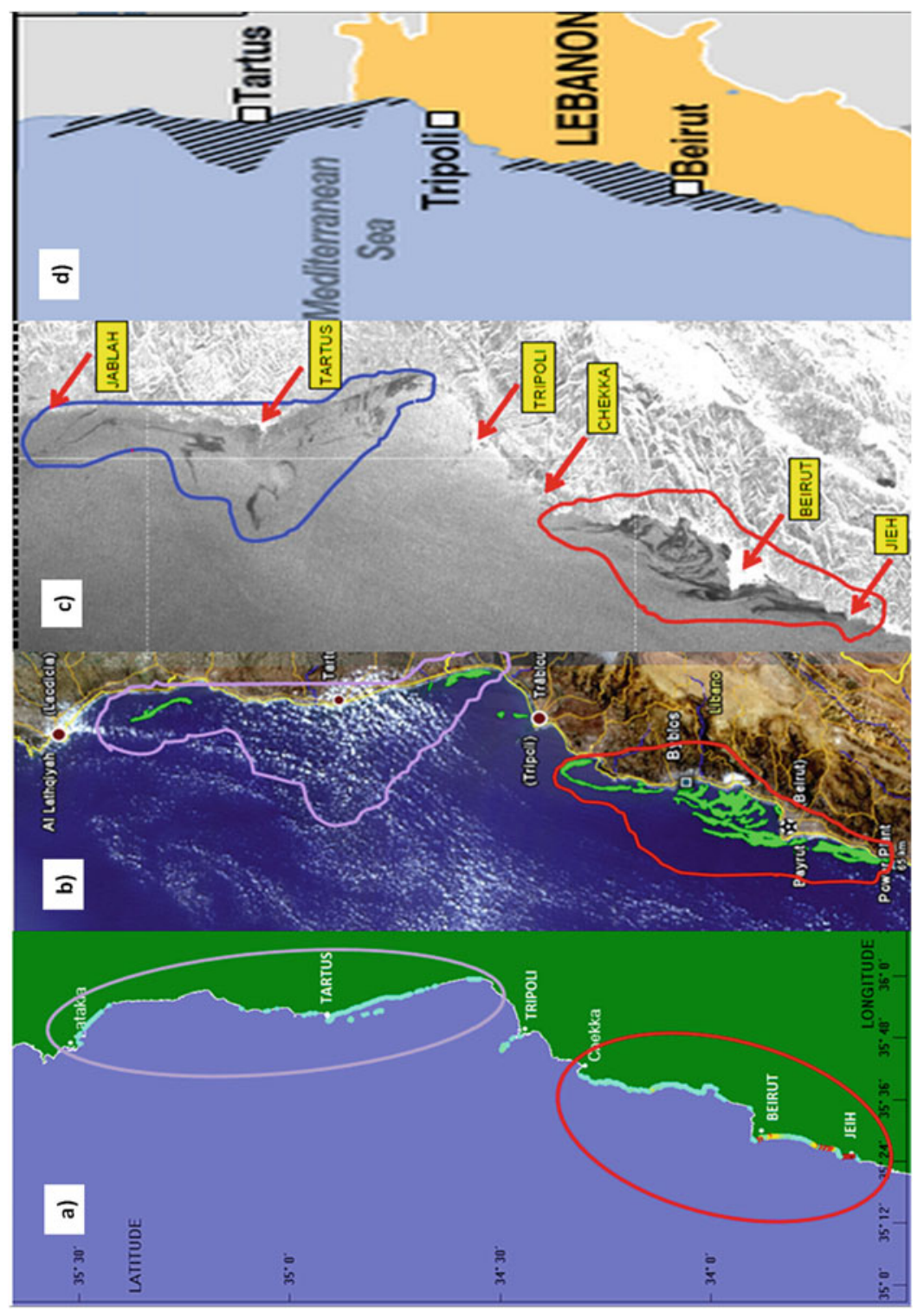

ปี

:

ธี สं

न

(ิ)

ฮี่

$\sum_{0}^{\infty}$

웜

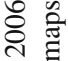

흐. 호

的

$\Xi$

is

흥

ธิ อำ

总 的

․욜

")

들.

จิ

\%

$\cong \stackrel{ \pm}{ \pm}$

일

쿵

ฮ స

$\infty$

흐 ᄂ

टे ह

?

空 :

可

is

合

○

흐는

बे

림

휴 है

눙

ठิ

光

氧亦

월 四

远

ఏ

$=\frac{0}{0}$

ติ 
were part of the European GMES initiative (Global Monitoring for Environment and Security, precursor of the European Copernicus service), which was co-funded by the ESA and EC.

These specific projects were part of the GMES Service Elements (GSE) program, aiming at delivering decision support systems for use by the public and the policymakers, with the capability of acquiring, processing, interpreting, and distributing information related to environment, risk management, and natural resources. The POSEIDON OSM was the forecasting component of the MARCOASTintegrated oil spill service, which was implemented in operational mode during a 3-year period (2006-2008) in the Aegean Sea. This later service was an integration of the oil spill detection processes applied on satellite-based SAR images, together with the forecast of oil spill evolution provided by the POSEIDON oil spill system (Fig. 12). The core user of this service was the Marine Environment Protection Division (MEPD) of the Greek Ministry of Mercantile Marine, which has the responsibility of surveying the Greek Seas. The users received near-real-time $(1 \mathrm{~h}$ after satellite overpass) synthetic information concerning oil spill detection and relevant forecasts in the Aegean Sea, through a dedicated Web site. Users were also alerted by e-mail/fax/telephone of new information posted to a dedicated Internet site [33].

The POSEIDON OSM was further upgraded into an active element of the European Decision Support System (EuroDeSS) in 2010, as part of the EC-funded ECOOP (European Coastal Sea Operational observing and Forecasting System, 2007-2010) project. This was achieved through the integration of ECOOP standard input and output formats, which extended the systems' interoperability, allowing data exchange and comparison experiments between different numerical models. During the implementation of the Aegean module of DESS, the system was used in operational mode in order to support the Greek marine authorities in their response to a real accident that took place in the North Aegean in 2009 [31].

During the Mediterranean Decision Support System for Marine Safety (MEDESS-4MS, 2012-2015) project funded by the MED Program, four different well-established oil spill models (MEDSLIK, POSEIDON-OSM, MOTHY, MEDSLIK-II) were integrated into a combined service running together with high-resolution environmental (meteorological and oceanographic) data from the Copernicus Marine Environment Monitoring Service (CMEMS) ${ }^{7}$ and associated national downscaled ocean forecasting systems from the MONGOOS network [27]. Oil slick data from existing monitoring platforms, such as REMPEC and EMSA CleanSeaNet satellite data, were also connected to the MEDESS-4MS service, thus building a complete oil spill response and decision support service.

\footnotetext{
${ }^{7}$ See www.marine.copernicus.eu.
} 


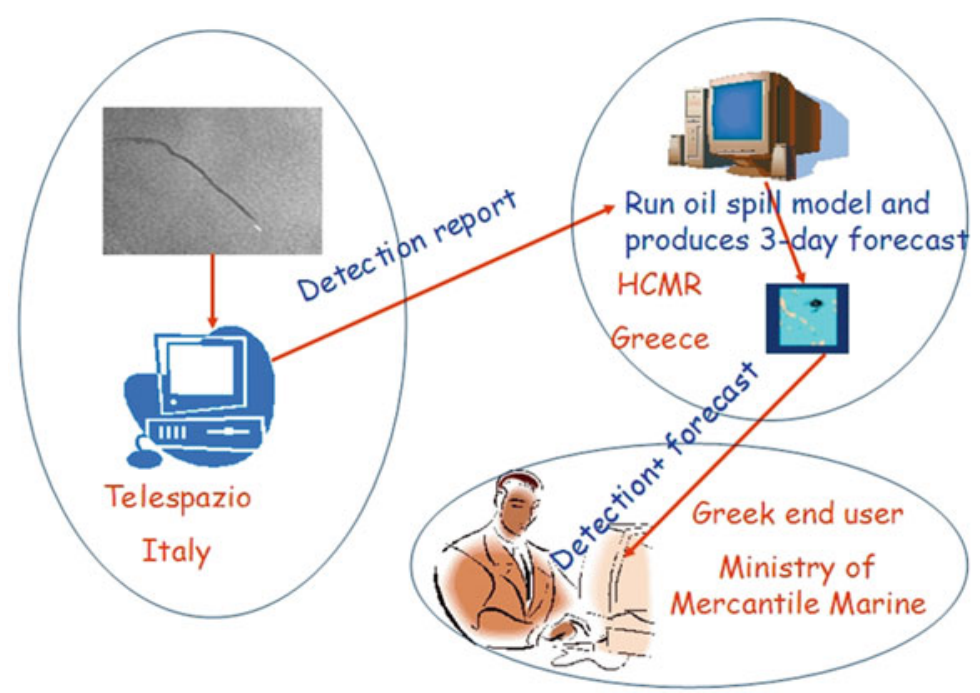

Fig. 12 Schematic representation of the integrated oil spill service in the Aegean Sea between 2006 and 2008

This multi-model oil spill prediction service is helpful to both EU and non-EU members' response agencies and to the key users such as REMPEC and EMSA.

The POSEIDON oil spill model is a fully 3D oil spill model capable of simulating the movement and spreading and aging of oil particles in the 3D space. The whole mass of the oil is represented by a large number of material particles or parcels, each representing a group of oil droplets of like size and composition. The oil transport is described by two modules, the circulation module and the wind-generated wave module. The horizontal displacement caused by advection, and the vertical transport of the oil, are calculated using the output of the oceanographic model. The net current speed caused by linear waves (Stokes drift) is calculated using the wave model output. The horizontal and vertical mixing coefficients of the hydrodynamic model are used to calculate the horizontal and vertical diffusions, while the vertical resolution of the model is tied to the relevant resolution of the hydrodynamic model.

The POSEIDON-OSM is also capable of simulating oil spill weathering transformations in the marine environment such as the evaporation, emulsification, beaching, and sedimentation of oil. The required input information consists of data specifying the event and the oil spill per se: location of the event (Lat/Long), date and time of the event, total volume of the oil released into the sea, number of particles describing the volume, critical density for evaporation and emulsification, retention time (how long an oil particle stays in the beach), evacuation time (instant disposal in the sea or not), and total time of model integration.

In the existing operational implementation of POSEIDON OSM, the model uses atmospheric data from the POSEIDON ETA weather forecasting system [34], wave 


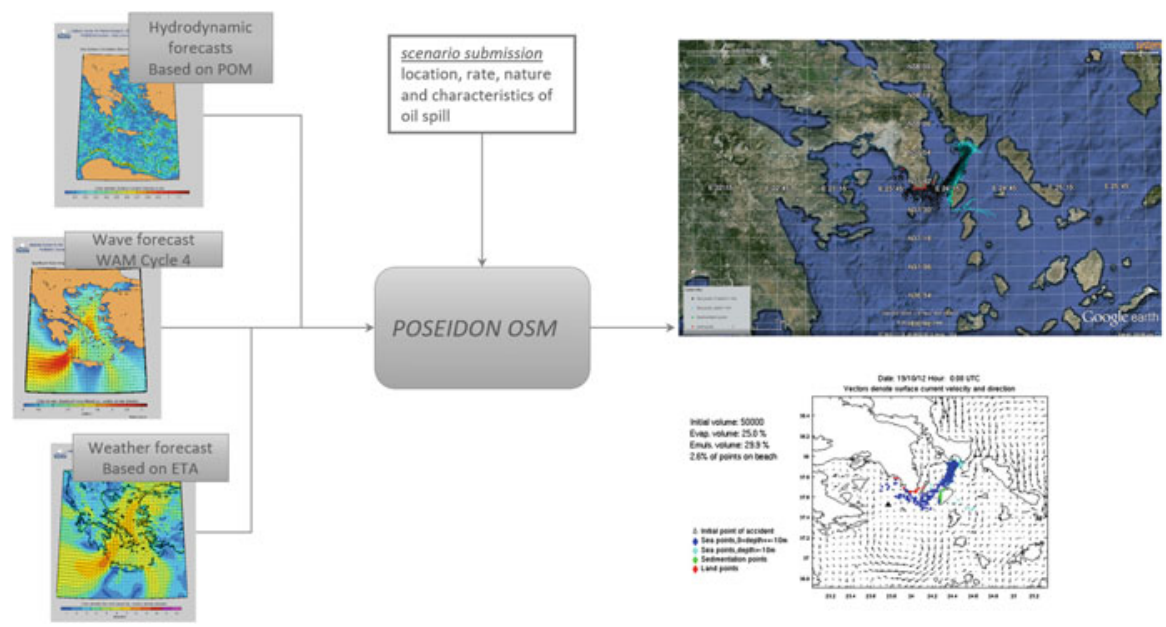

Fig. 13 Schematic representation of the POSEIDON OSM simulation process

data from the POSEIDON WAM Cycle 4 for the Aegean Sea [35], and oceanographic data from the POSEIDON Aegean model [7]. The forecast length extends from few hours up to the present-day availability of the required forcing data (typically 5 days). In Fig. 13, a schematic representation of the POSEIDON OSM simulation process is shown for a hypothetical incident in the Aegean Sea.

The predicted output variables of the model contain the position of each particle in the sea (longitude, latitude, and depth), the evaporated volume of the initial oil, the emulsified volume, the volume remaining on the beach, and the oil volume that reached the sea floor.

Currently, the POSEIDON oil spill model can be triggered through a dedicated Web-based application ${ }^{8}$ (see Fig. 14) where the user can specify the parameters of a real or hypothetical event and submit this scenario to the system, receiving the results after a few minutes. There is also the possibility for the user to receive the results in Google Earth format for a more realistic geospatial representation.

\subsection{POSEIDON OSM Test Cases}

No major oil spill accidental events have occurred in the Greek Seas since the implementation of the POSEIDON OSM in 2000, so that the model could be tested and validated during real-time accidents. Nevertheless, POSEIDON oil spill service has been frequently used as a decision support system under the framework of distinct European projects, as well as to support the Greek marine authorities in the

\footnotetext{
${ }^{8}$ Available at http://osm.hcmr.gr.
} 


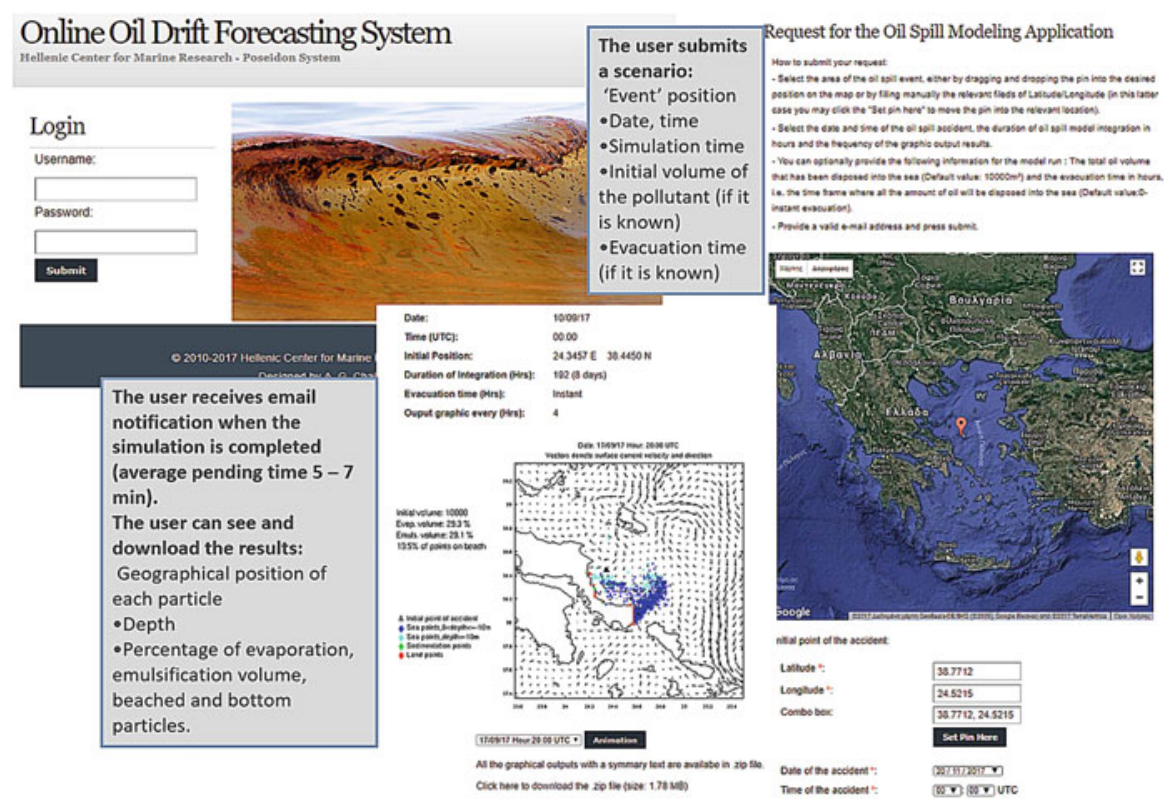

Fig. 14 The POSEIDON OSM Web interface

prevention of pollution in the marine environment during real oil spill and ship collision incidents. A case of a real accident in the North Aegean Sea will be described subsequently, along with some test cases during field experiments completed during the MEDESS-4MS project.

During the implementation of the ECOOP project, the developed Aegean Decision Support System was used in operational mode to support the responsible Greek marine authorities (Ministry of Mercantile Marine, Marine Environment Pollution Division) handling a real accident that took place in the North Aegean area at the end of June 2009 [31].

The accident that alerted the Greek authorities was a collision between two cargo ships in the international waters of the Northeast Aegean Sea during the night of 27 June 2009. Although no significant amount of oil was initially spilled into the sea, the situation remained critical for several days as the two ships were joined together after the collision and they were towed slowly toward the Turkish coasts. The Greek authorities requested (from REMPEC) the activation of the agreement between REMPEC and MONGOOS to assist in preventing and minimizing any possible threat(s) of marine pollution to Greek territorial waters as well as to the Greek islands, resulting from the collision incident.

As a MONGOOS member, the HCMR responded to this request by implementing the new developed Aegean Sea Decision Support System into operational mode. Every day, a complete report with the evolution of the oil spill for the next 2 days was provided to relevant ministries in order to help in planning the possible actions in case of a major release of oil into the sea. For the production of 
daily forecasting information, the POSEIDON atmospheric and marine background data was converted into the common standard NetCDF format and was then fed into the system, as required by the previously mentioned Aegean DESS specifications. Finally, this alert situation ended without any further events 3 days later - with the safe towing of the two ships onto the Turkish coast.

In the framework of MEDESS-4MS project, two sea field experiments were organized in order to evaluate the performance of the oil spill forecasting service. One of them was conducted in connection with the RAMOGEPol exercise and took place in Portoferraio, north of the Elba Island, between 16 and 17 September 2014. The Italian Ministry of Environment organizes the RAMOGEPol exercise every year in cooperation with relevant authorities in France, Italy, Monaco, and Spain to evaluate the efficiency and organization of each country in the field of preparedness for response to marine pollution from ships.

In September 2014, three OCEANIA Long Range (LR) Buoys, equipped with satellite transmission to track the oil spill at long-range distances, were released by the CEDRE representative from the Italian Coast Guard vessel into an area infused with rice husks, used as pollutant at the hypothetical accident position. The aim of this exercise was to check how efficiently the buoys behave as the pollutant-like substance by showing a similar drift and then to compare their trajectory with the dispersion calculated from the forecasting models. The three buoys remained in the path of the pollutant-like substance throughout the duration of the exercise $(6 \mathrm{~h})$, while the POSEIDON OSM was chosen among the other MEDESS-4MS models to simulate the oil dispersion during the exercise. The drift of the satellite transmitting buoys was compared with the drift of the trajectory provided by POSEIDON OSM. Both showed similar southwestward trajectories as illustrated in Fig. 15, and thus it can be assumed that POSEIDON OSM corrected the drift of the rice husks, the pollutant-like substance of the exercise.

\section{MEDSLIK-II: A Community Oil Spill Model for the Mediterranean}

An oil spill model MEDSLIK-II [12, 24], based on its precursor oil spill model MEDSLIK [11, 36], has been freely available to the scientific community ${ }^{9}$ since 2012.

The model is used to predict oil transport and transformation due to complex physical processes occurring at the sea surface. Within the framework of a Lagrangian approach, the oil slick is discretized into constituent particles. Each particle moves due to currents, wind, and waves, whose parameters can be obtained from external basin-scale or subbasin oceanographic and atmospheric models. The oil transformation processes at the surface are calculated by means of bulk formulas

\footnotetext{
${ }^{9}$ See http://medslikii.bo.ingv.it/.
} 


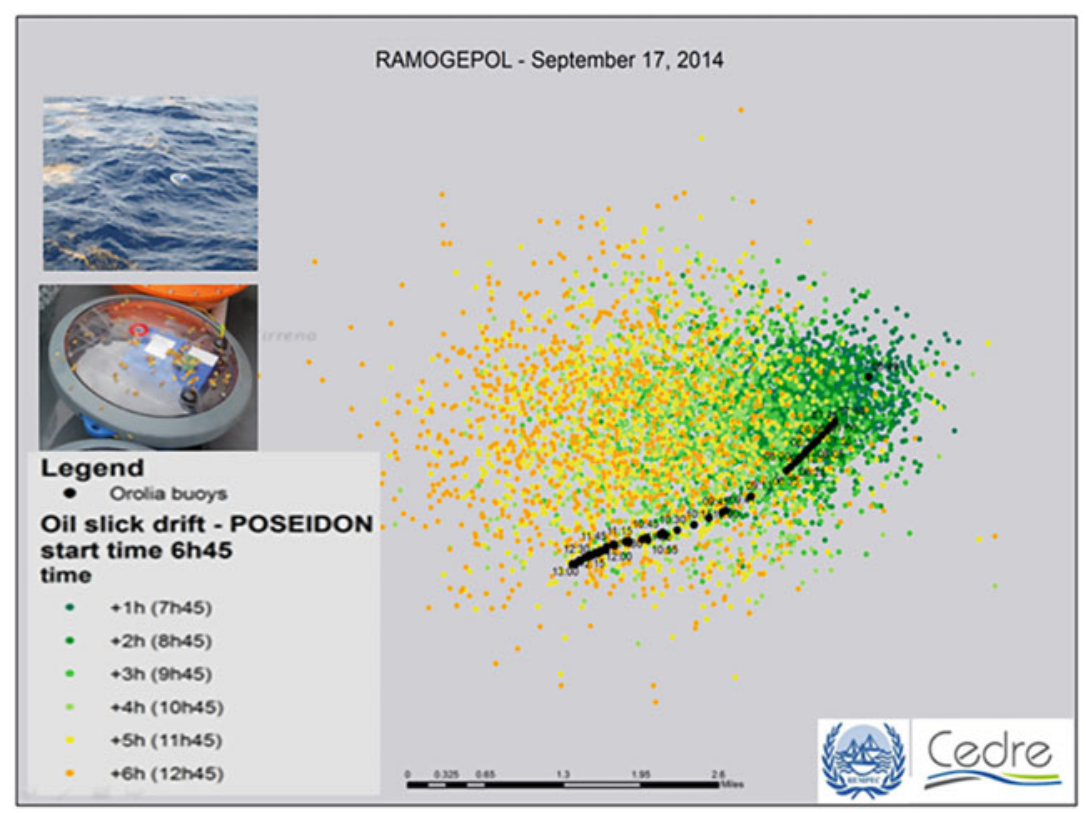

Fig. 15 Map representing the buoys trajectories from 17 September 2014 at 6:45 up to 12:30 compared to the POSEIDON OSM predictions

that describe changes in surface oil volume due to three main processes, known collectively as weathering (evaporation, dispersion, and spreading). The formation of water-in-oil emulsion is also taken into consideration. If oil droplets arrive on the coast, the model is able to simulate the adsorption of droplets into the coastal environment, taking into account the probability that oil may be washed back into the water. As key outputs, MEDSLIK-II provides the oil concentrations at the surface, in the dispersed water-column fraction, and on the coast. Mass balance components of the oil are calculated as a function of time, which allows a timedependent tracking on the oil weathering.

A scientific consortium was established in November 2012 with the aim of bringing MEDSLIK-II into operation and ensuring its continued, sustainable development and application as a state-of-the-art software suitable for a wide range of users. Currently, the consortium embraces the Istituto Nazionale di Geofisica e Vulcanologia (Italy), the Euro-Mediterranean Center on Climate Change (Italy), the Consiglio Nazionale delle Ricerche - Istituto per lo Studio dell'Ambiente Marino Costiero (Italy), and the MEDSLIK developers from the Oceanography Center at the University of Cyprus (Cyprus) and the Simon Fraser University (Canada), as well as more than 300 active users around the world.

For the period of the consortium activity, MEDSLIK-II has been developed and extensively applied to a wide variety of practical tasks. Primarily, the model's parametric sensitivity was tested, and the accuracy was evaluated against synthetic aperture radar (SAR) and optical satellite images of oil slicks and passive drifter 
trajectories in different areas of the Mediterranean Sea - including an Algerian case experiment [24].

It was concluded that MEDSLIK-II forecasts largely depend on the spatialtemporal resolution of ocean currents provided by the operational Eulerian models. In addition, key effects on the model were proven for local wind velocity correction and the wave-induced current terms (the Stokes drift velocity). Since then, an empirical JONSWAP wave spectrum computed as a function of wind speed and fetch [37] has been algorithmically incorporated into the model to calculate the Stokes drift components. Recently, MEDSLIK-II was adjusted [38] for the direct use of WaveWatch-III model outputs [39], which seem to be more accurate and computationally efficient than the JONSWAP parameterization.

The new generation of oil spill models requires not only spill forecasts but also the evaluation of uncertainty of such forecasts, which is itself critical for timely, efficient, and cost-effective responses. Uncertainty in the prediction of the oil transport and transformation stems from uncertain environments and sparse data. Due to a large number of parameters that control the oil movement and transformation in MEDSLIK-II, the number of possible uncertainty scenarios is enormous. Currently, MEDSLIK II started to implement both simple and efficient algorithms to quantify uncertainties caused by the initial oil spill conditions [48], ocean currents, and wind [49].

Milestones in MEDSLIK-II research, development, and applications are listed in Table 1.

\subsection{The MEDSLIK II Test Case: The Case of Costa Concordia}

During the Costa Concordia emergency, the capabilities of basin-scale, sub-basin, and local relocatable ocean circulation models were tested as the external providers of ocean dynamics data for the MEDSLIK-II oil spill model [40]. On 13 January 2012, only hours after leaving the Italian Port of Civitavecchia, the Costa Concordia cruise ship - with more than 4,200 passengers and crew on board - hit a rocky outcrop, ran aground, and rolled onto its side as it sailed off Giglio Island in Italy (Fig. 16). With 2,500 tons of fuel in her tanks, the Costa Concordia was immediately considered a high-risk accident in terms of possible oil spills.

The Coast Guard and Civil Protection authorities immediately reacted by triggering off a search and rescue operation and elaborate risk mitigation measures. In case of failure of the debunkering operation, a spillage might have polluted a marine environmental protected area of the Tuscan Archipelago National Park. Every day, starting from the 16th of January and until the fuel unloading operations finished, the MEDSLIK-II model was run to produce forecasts for a possible oil spill sourced from the Costa Concordia. Daily bulletins were provided to the Italian Coast Guard Operational Center. Those bulletins presented forecasts of ocean 
Table 1 Main steps of MEDSLIK-II progress in research, development, and applications

\begin{tabular}{|c|c|c|c|c|}
\hline \#\# & Activity & Date & $\begin{array}{l}\text { Mediterranean } \\
\text { subbasin if } \\
\text { applicable }\end{array}$ & Reference \\
\hline 1 & $\begin{array}{l}\text { Oil pollution hindcast during the Lebanon cri- } \\
\text { sis, } 2006\end{array}$ & 2011 & $\begin{array}{l}\text { Eastern } \\
\text { Mediterranean }\end{array}$ & [5] \\
\hline 2 & $\begin{array}{l}\text { Publishing in the Internet as an open-source } \\
\text { scientific tool }\end{array}$ & 2012 & & $\begin{array}{l}\text { medslikii. } \\
\text { bo.ingv. } \\
\text { it/ }\end{array}$ \\
\hline 3 & Publishing a full MEDSLIK-II description & 2013 & & [12] \\
\hline 4 & $\begin{array}{l}\text { Parameter tuning and sensitivity analysis } \\
\text { against SAR and optical satellite images of oil } \\
\text { slicks, Algeria case experiment }\end{array}$ & 2013 & $\begin{array}{l}\text { Western and } \\
\text { eastern }\end{array}$ & [24] \\
\hline 5 & $\begin{array}{l}\text { Support of the Costa Concordia accidental } \\
\text { debunkering and parbuckling }\end{array}$ & $\begin{array}{l}2012 \\
2013\end{array}$ & $\begin{array}{l}\text { Western } \\
\text { Mediterranean }\end{array}$ & [40] \\
\hline 6 & $\begin{array}{l}\text { Testing the multi-model forcing on ocean } \\
\text { currents }\end{array}$ & 2014 & $\begin{array}{l}\text { Western } \\
\text { Mediterranean }\end{array}$ & [40] \\
\hline 7 & $\begin{array}{l}\text { Improving the representation of beaching in the } \\
\text { case of Lebanon crisis }\end{array}$ & 2014 & $\begin{array}{l}\text { Eastern } \\
\text { Mediterranean }\end{array}$ & [46] \\
\hline 8 & $\begin{array}{l}\text { Multi-model forcing on the combination of } \\
\text { currents, waves, and winds, the MEDESS4MS } \\
\text { Serious Game experiment }\end{array}$ & 2014 & $\begin{array}{l}\text { Western } \\
\text { Mediterranean }\end{array}$ & [38] \\
\hline 9 & $\begin{array}{l}\text { HPC MEDSLIK-II ensemble simulations for } \\
\text { hazard assessment }\end{array}$ & $\begin{array}{l}2015 \\
2016\end{array}$ & $\begin{array}{l}\text { Eastern } \\
\text { Mediterranean }\end{array}$ & {$[47,48]$} \\
\hline 10 & $\begin{array}{l}\text { Algorithms of uncertainty penetration through } \\
\text { MEDSLIK-II }\end{array}$ & $\begin{array}{l}2015 \\
2017\end{array}$ & & {$[48,49]$} \\
\hline 11 & $\begin{array}{l}\text { User-oriented Web-based decision support sys- } \\
\text { tem WITOIL }\end{array}$ & 2016 & & [48] \\
\hline
\end{tabular}

currents and wind and oil concentration on an hourly basis. As an oil spill scenario could not be totally discarded, this information would have been crucial for planning the prevention measures of a hypothetical oil spill, thus optimizing the cleaning operations. Similar MEDSLIK-II calculations were carried out during the Costa Concordia parbuckling ${ }^{10}$ in September 2013 (Fig. 17).

To compute the possible scenarios of fuel leaks, MEDSLIK-II was operationally linked [40] with a suite of ocean circulation models including (1) the basin-scale Mediterranean Forecasting System MFS [41]; two subregional models: (2) the Western Mediterranean WMED [42], (3) the Tyrrhenian Sea TYRR [43]; and (4) the high-resolution Interactive Relocatable Nested Ocean Model (IRENOM). The latter model can be deployed at any local area of the Mediterranean in a very short time as required by the management of emergencies caused by oil spills or contaminant release(s) at sea. The accuracy of the simulations was evaluated during a field experiment with the release of four i-SPHERE drifters in the area of the

\footnotetext{
${ }^{10}$ Is the righting of a sunken vessel using rotational leverage.
} 


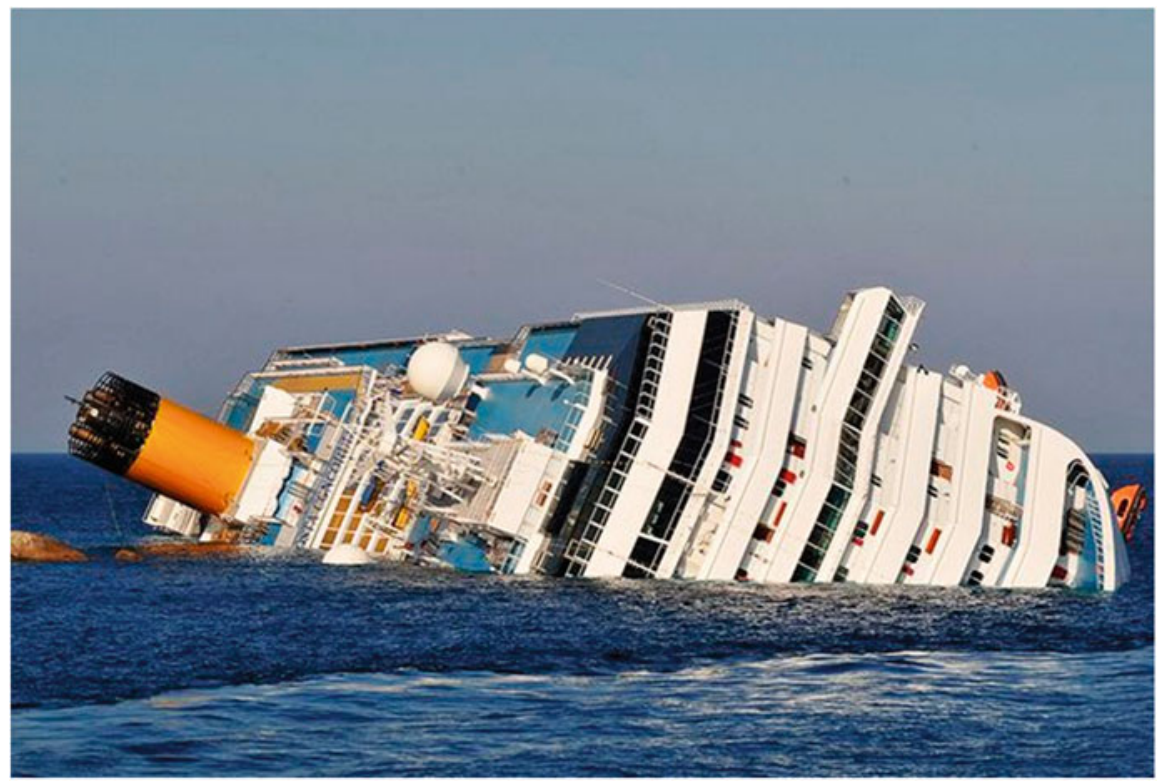

Fig. 16 Costa Concordia accident (Photo: Getty). http://www.mirror.co.uk/news/world-news/ doomed-costa-concordia-was-carrying-5432140

accident. Being transported by ocean currents, the oil spill following-surface drifters (i-SPHERE) were designed to emulate oil drift at the sea surface [44]. Over the experiment, the highest skill score in the predictions of drifter trajectories was achieved by the IRENOM model with respect to both metrics of the trajectory separation distance and the skill score imposed by [45]. Thus, for the first time, a multi-model approach in oil spill modeling was implemented. Combining multiple oceanographic forcing, it was demonstrated [40] that such an approach could provide a higher degree of confidence than any single forcing alone.

Recently, De Dominicis et al. [38] enhanced the approach above by adding multi-model waves (Stokes drift) and winds. The MEDSLIK-II outputs were validated during a field exercise, called MEDESS4MS Serious Game, in the Elba Island area in May 2014. Satellite images covering the exercise area were acquired on an operational basis. Italian Coast Guard ship was sent to confirm the presence of oil slicks found remotely to the source area. Drifters with different water-following characteristics were deployed into the slick and then monitored over the following days. Oil slick observations (from satellite and ship) and drifter trajectories were then used to evaluate the quality of MEDSLIK-II forecasts (Fig. 18). The authors described the parametric tuning MEDSLIK-II in detail, focusing on uncertainties in underlying physics.

Oil-shoreline interaction, or the so called "beaching," is an essential part of oil spill impact assessment, as it regards the definition of the location and extent of oiled shorelines, the amount of oil that reaches and stays at the shore, as well as the 


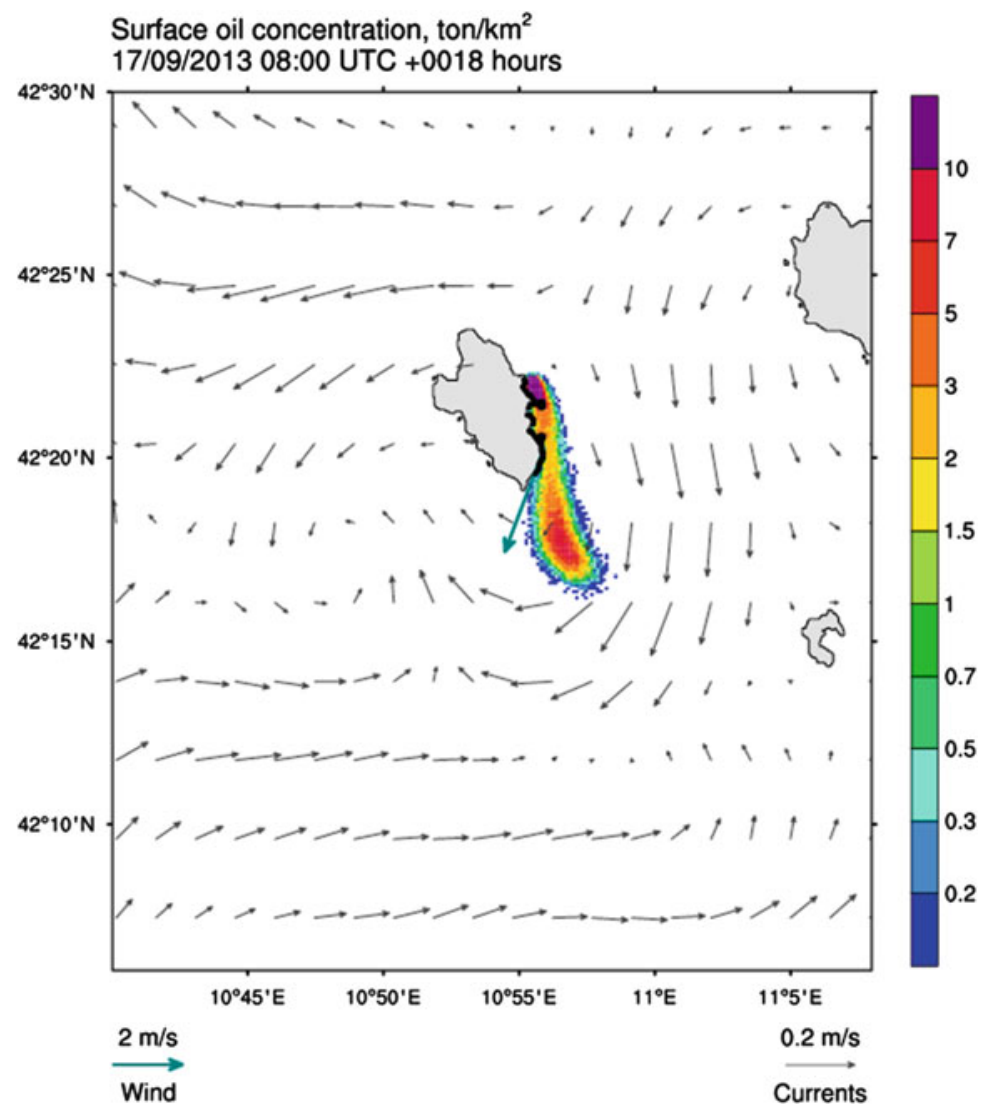

Fig. 17 Example of an oil spill forecast during the Costa Concordia parbuckling in September 2013

temporal characteristics of the processes in action. Representing these processes by MEDSLIK-II was efficiently studied for the Lebanon oil spill of 2006 [46].

High-performance computing (HPC) has stimulated ensembles of MEDSLIK-II calculations. An original methodology [47] of oil pollution hazard mapping was developed based on (1) the UNESCO definition of hazard, (2) actual ship traffic distributions provided by the Italian Coast Guard (ITCG), (3) ensemble runs of MEDSLIK-II, and (4) operational analyses from the Mediterranean Forecasting System (MFS) and the European Centre for Medium-Range Weather Forecasts (ECMWF). This methodology (Fig. 19) was applied to operational oil spill events in the southern Adriatic and northern Ionian Seas and relied on statistically confident simulations.

Overall, several hundred thousand MEDSLIK-II simulations were performed during the 2009-2013 time period. The hazard maps obtained (Fig. 20) were considered representative of future events under the assumption that the traffic 

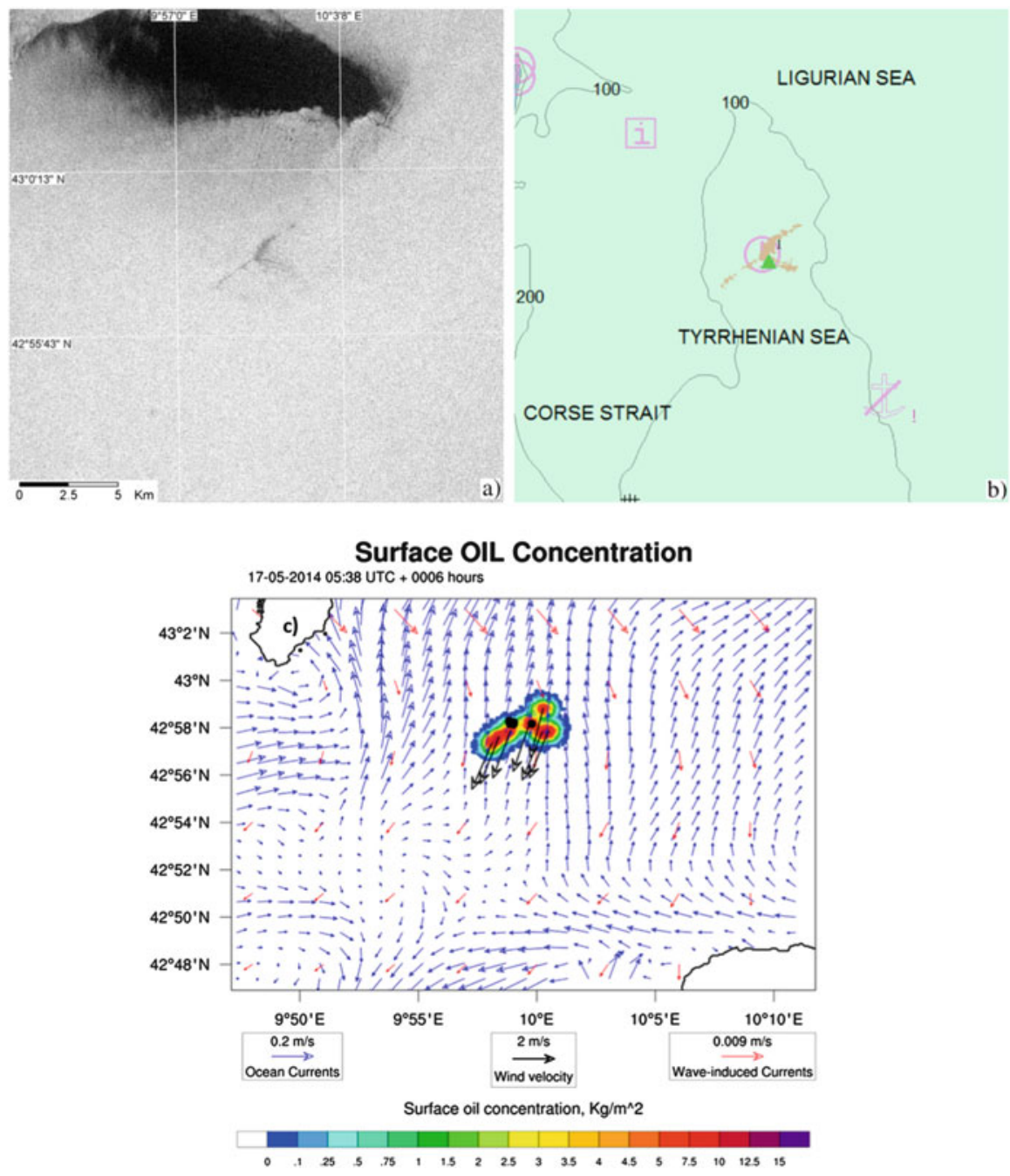

Fig. 18 (a) Oil slick remote detection, (b) geo-referencing, and (c) tracking by MEDSLIK-II during the MEDESS4MS Serious Game, May 2014. In (c), black dots depict the observed oil slick locations, while the color patterns indicate the model distribution (maps from De Dominicis et al. [38])

density distribution and the amount of oil operationally spilled were representative of the present state and will follow the estimated tendencies in the future, and the historical database of met-oceanographic conditions contained a realistic sample of possible weather and sea state conditions.

This methodology was also used to quantify the hazards that caused possible accidental oil spills from six (6) oil production platforms situated on the Adriatic shelf [48]. 
G. Zodiatis et al.

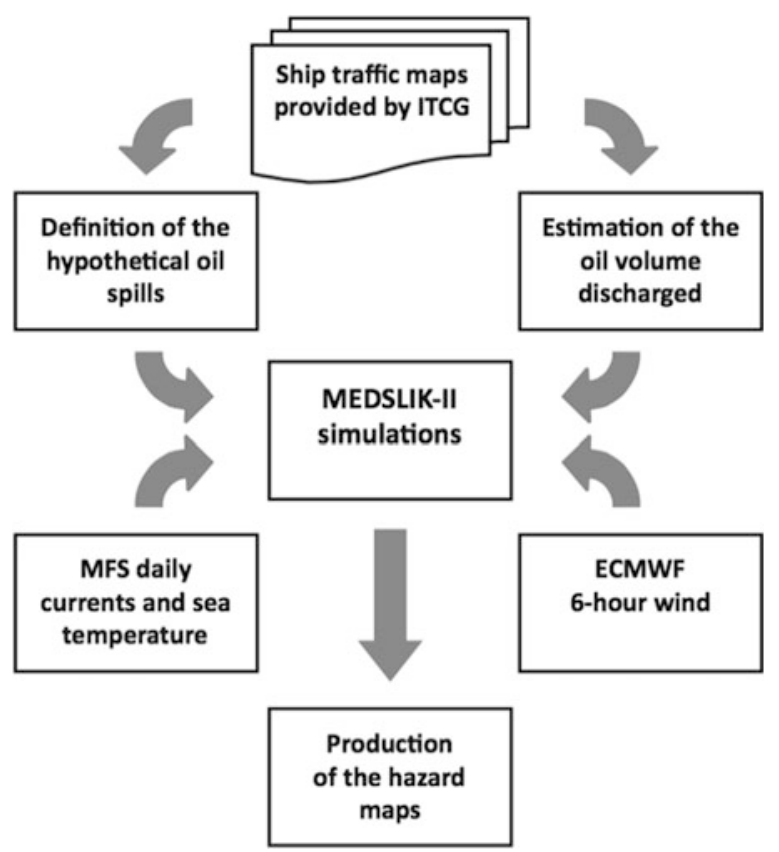

Fig. 19 Schematic diagram of the oil pollution hazard mapping methodology (diagram from Liubartseva et al. [47])

Finally, an innovative fully operational 24/7 Web-based decision support system, WITOIL ${ }^{11}$ (Where Is The Oil), has been developed [48]. To compute the oil transport and transformation, WITOIL uses MEDSLIK-II forced by operational met-oceanographic datasets provided by the Copernicus Marine Environment Monitoring Service $\left(\mathrm{CMEMS}^{12}\right)$. Results of the modeling are visualized through Google Maps. The system meets the real-time requirements in terms of performance and dynamic service delivery. Comprehensive computational resources and network bandwidth efficiently support the multiuser regime. The eight-language graphical user interface (Fig. 21) incorporates a great variety of user services, e.g., help and support, tooltips, and video tutorials. A special application for Android is designed to provide mobile access for competent authorities, technical and scientific institutions, and also to citizens.

\footnotetext{
${ }^{11}$ http://www.witoil.com.

${ }^{12} \mathrm{http}: / /$ marine.copernicus.eu.
} 

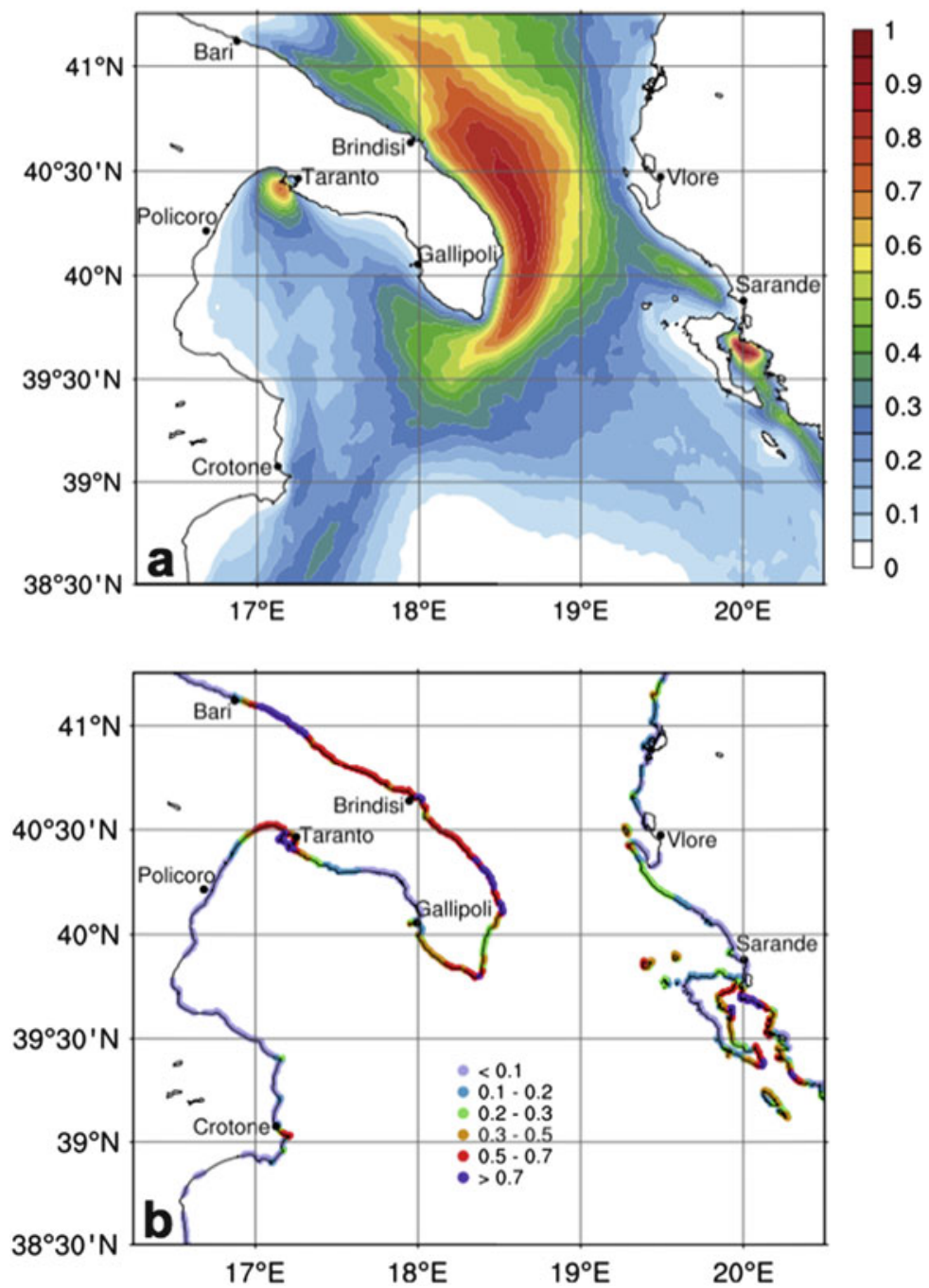

Fig. 20 Averaged 2009-2012 hazard maps in probability terms (a) at the sea surface and (b) on the coastline, in the Southern Adriatic and Northern Ionian Seas (maps from Liubartseva et al. [47])

\section{Oil Spill Risk Mapping}

In this chapter, we demonstrated that following the identification of a spill, operational oil spill modeling could support contingency field activities, forecasting the fate of the contaminant. Another way to support emergency management is to use oil spill risk mapping, offering an immediate response (order of few tens of minutes) to where is the likely oil spill movement and the potential impacts on the coasts. Oil spill risk mapping is a young science and it gives a complementary 


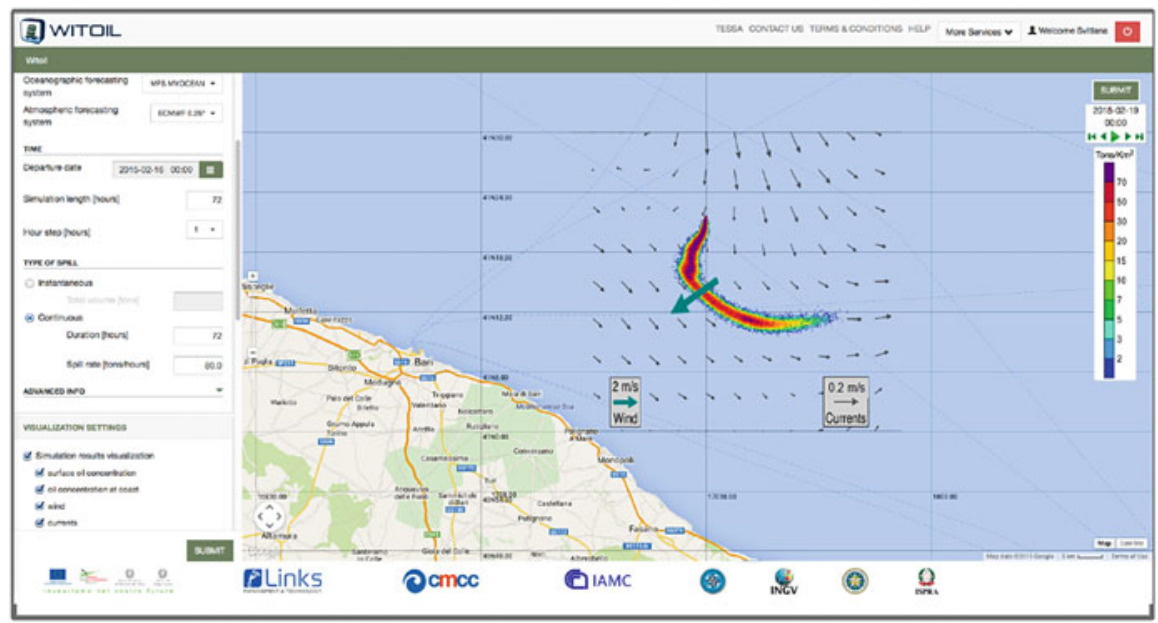

Fig. 21 A screenshot of the WITOIL user interface after the simulation of oil spill forecast (map from Liubartseva et al. [48])

input to operational oil spill forecasting for management of emergencies at sea. Oil spill risk mapping allows also estimating uncertainties and present the oil spill hazard in terms of probability distributions.

The literature on oil spill risk and hazard mapping is vast $[47,50]$ and suggests that there is no unique concept of risk, vocabulary, and hazard/risk quantification methods within the community. The lack of standards makes comparisons between hazard levels estimates by different studies unfeasible and, therefore, difficult to depict a global oil spill hazard scenario and the threat it might represent to our coast. An attempt to propose a theoretical framework for oil spill risk assessments based on the international standard ISO 31000:2009 and adapted to the specificities of the oil spill problem was presented by Sepp Neves et al. [51] using the IT-OSRA methodology. The core of the IT-OSRA methodology consisted on employing ensemble oil spill simulations to estimate not only the hazard but also its uncertainties.

Sepp Neves et al. [51] performed a case study employing IT-OSRA to the Lebanon summer 2006 oil spill case, in which were proposed nine ensemble members addressing uncertainties/inconsistencies identified in the available accident reports, namely the volume of oil spilled and its density, when the spill started and its donation. Based on the ensemble average of oil concentrations at the model coastal segments, an oil spill hazard map (Fig. 22a) and its uncertainties (Fig. 22b) were produced.

Comparisons between the hazard maps produced by IT-OSRA method (Fig. 22a) along the Lebanon coasts and in situ oil observations during summer 2006 [52] (Fig. 23a) demonstrate that areas with an assigned high hazard level are compatible with most of the areas actually impacted by the oil spill. The hazard estimates, combined with a coastal vulnerability map [53], were used to quantify the risk (Fig. 23b). 

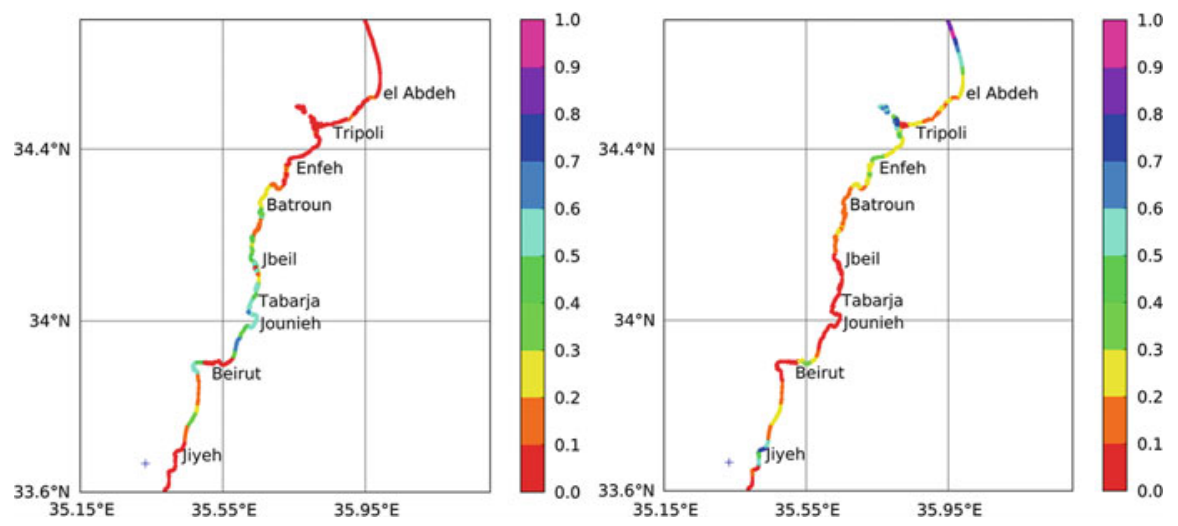

Fig. 22 Oil spill hazard levels (a) and its uncertainties (b) estimated for the Lebanese coast [51]. For the hazard maps, the values represent the ratio between the ensemble average concentration for a given segment and the maximum value observed in the study area. Similar strategy was used to compute the uncertainties, here the ratio between the local coefficient of variation and the maximum value observed in the study area. (Figures reproduced from Sepp Neves et al. [51])
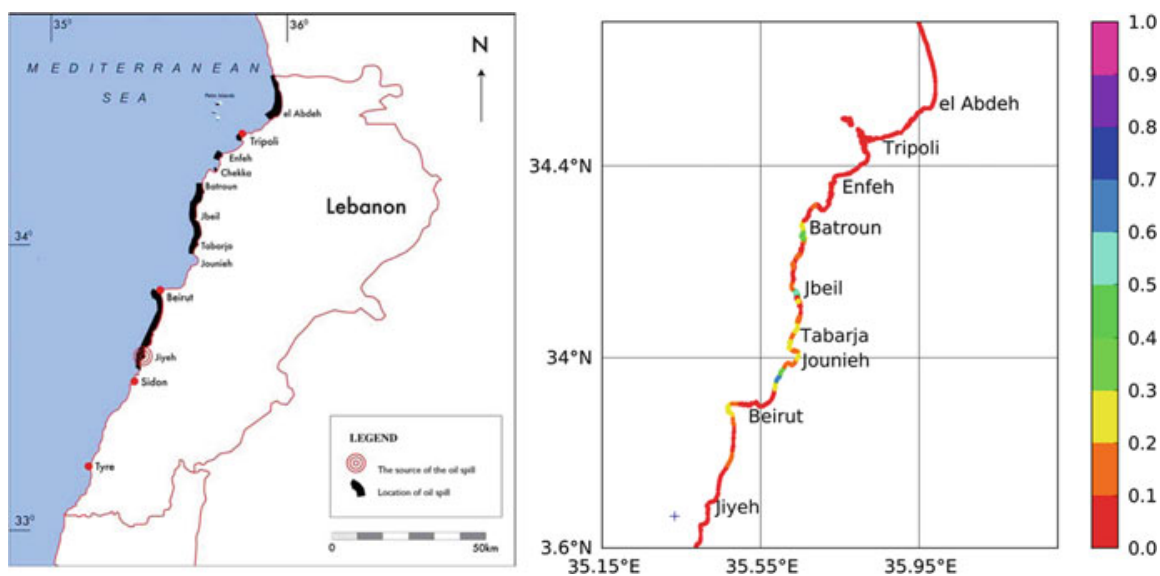

Fig. 23 In situ oil observations extracted from Green Line Association (2007) (a) and the final map of oil spill risk for the Lebanese coast (b) reproduced from Sepp Neves et al. [51]. Areas with a risk index closer to 1 are exposed to higher levels of risk than areas with risk values closer to 0

Moreover, the IT-OSRA method has been applied to a larger scale experiment in Southern Portugal [54] using again a multi-model, multi-physics approach. In this work, it is shown that computing averages of coastal concentrations supposing a Gaussian distribution of the oil at the coasts might not fit the numerical simulation data and work is underway to quantify the statistical nature of the coastal oil spill distributions. 


\section{Conclusions}

Despite political, social, and economical differences and problems among the riparian countries of the Eastern Mediterranean Sea, all of them have ratified the protocols of the Barcelona Convention and are members of REMPEC. In parallel, EC member states in the region and those associated to the EC are members of EMSA-CSN. Within the frame of these organizations, the national response agencies in the Eastern Mediterranean - through the coordination actions of REMPEC and EMSA-CSN - cooperate to mitigate and fight major oil pollution incidents at the national, subregional, and regional scales.

Within the first trilateral cooperation between Cyprus, the Arab Republic of Egypt, and the State of Israel for preparedness and response to major oil spill accidents in the Eastern Mediterranean Sea, in the late 1990s, oil spill modeling was set at the forefront of any contingency plans. During the Lebanon oil pollution of summer 2006, the operational predictions of the advection of the spilled oil, completed by the MEDSLIK model, provided to neighboring nations a reliable daily picture of the extent of the oil slick and of the affected coastline, for the entire period of the pollution crisis.

Nowadays, the enlargement of the Suez Canal and the expansion of oil/gas exploration and production in the Levantine Basin render oil spill modeling prediction to be a pre-requirement to contingency plans and a necessary tool to the response agencies.

With the development and implementation of operational oceanography in the Mediterranean Sea, as one of the CMEMS regions, and the provision of satellite SAR images detecting possible oil slicks, it is now possible to obtain near-real-time operational oil spill modeling predictions. The successful implementation of EC projects addressing the oil spill modeling in the Mediterranean, particularly MEDESS-4MS, resulted in the harmonization of the input/output information for the needs of oil spill modeling, setting in this way the "basic standards" for oil spill models in the region.

In summary, the cooperation between the oceanographic community of MONGOOS and REMPEC as well as with EMSA-CSN in oil spill modeling issues offered the possibility to all the nations of the region to have access to oil spill predictions, even if at national level they have not yet been established. This is also the case for nations that cannot access a well-established oil spill model, such as MEDSLIK, POSEIDON-OSM, or MEDSLIK-II. Following this same path, the MONGOOS initiative to set the MEDSLIK II as a community oil spill model is aiming to attract young scientists to attain further improvements and developments in oil spill modeling. 


\section{References}

1. IEA (2004) International Energy Agency, Natural Gas Information online database. https:// www.iea.org/statistics/relateddatabases/naturalgasinformation/

2. ITOPF (2015) The International Tanker Owners Pollution Federation Limited, oil tanker spill statistics 2015

3. Regional Maritime Pollution Emergency Response for the Mediterranean Sea (REMPEC) (2008) Study of maritime traffic flow in the Mediterranean Sea, final report, July. http://www. rempec.org/admin/store/wyswigImg/file/Prevention/Maritime\%20Study/Study\%20of\%20Mariti me\%20Traffic\%20Flows\%20in\%20the\%20MedSea_Unrestricted.pdf

4. Alves TM, Kokinou E, Zodiatis G, Radhakrishnan H, Panagiotakis C, Lardner R (2016) Multidisciplinary oil spill modeling to protect coastal communities and the environment of the Eastern Mediterranean Sea. Sci Rep 6:36882. https://doi.org/10.1038/srep36882

5. Coppini G, De Dominicis M, Zodiatis G, Lardner R, Pinardi N, Santoleri R, Colella S, Bignami F, Hayes D, Soloviev D, Georgiou G, Kallos G (2011) Hindcast of oil spill pollution during the Lebanon Crisis, July-August 2006. Mar Pollut Bull 62:140-153

6. Zodiatis G, Lardner R, Hayes DR, Georgiou G, Sofianos S, Skliris N, Lascaratos A (2008) Operational ocean forecasting in the Eastern Mediterranean: implementation and evaluation. Ocean Sci 4:31-47. https://doi.org/10.5194/os-4-31-2008

7. Korres G, Nittis K, Perivoliotis L, Tsiaras K, Papadopoulos A, Hoteit I, Triantafyllou G (2010) Forecasting the Aegean Sea hydrodynamics within the POSEIDON-II operational system. J Operat Oceanogr 3:37-49

8. Sofianos SS, Skliris N, Mantziafou A, Lascaratos A, Zodiatis G, Lardner R, Hayes D, Georgiou G (2006) Nesting operational forecasting models in the Eastern Mediterranean: active and slave mode. Ocean Sci Discuss 3:1225-1254

9. Korres G, Lascaratos A (2001) The Aegean-Levantine Eddy Resolving MOdel (ALERMO): implementation and climatological runs. Rapp Comm Int Mer Medit 36:70

10. Kallos G, Nickovic S, Papadopoulos A, Jovic D, Kakaliagou O, Misirlis N, Boukas L, Mimikou N, Sakellaridis G, Papageorgiou J (1997) The regional weather forecasting system SKIRON: an overview. In: Proceedings of the symposium on regional weather prediction on parallel computer environments, p 17

11. Zodiatis G, Lardner R, Solovyov D, Panayidou X, De Dominicis M (2012) Predictions for oil slicks detected from satellite images using MyOcean forecasting data. Ocean Sci 8:1105-1115

12. De Dominicis M, Pinardi N, Zodiatis G, Lardner R (2013a) MEDSLIK-II, a Lagrangian marine surface oil spill model for short term forecasting, Part 1: Theory. Geosci Model Dev 6:1851-1869

13. Lardner R, Zodiatis G (2017) Modeling oil plumes from subsurface spills. Mar Pollut Bull. https://doi.org/10.1016/j.marpolbul.2017.07.018

14. Tiago AM, Kokinou E, Zodiatis G, Lardner R, Panagiotakis C, Radhakrishnan H (2015) Modeling of oil spills in confined maritime basins: the case for early response in the Eastern Mediterranean Sea. Environ Pollut 206:390-399

15. Goldman R, Biton E, Brokovich E, Kark S, Levin N (2015) Oil spill contamination probability in the southeastern Levantine basin. Mar Pollut Bull 91:347-356

16. Brenner S (2015) Oil spill modeling in the southeastern Mediterranean Sea in support of accelerated offshore oil and gas exploration. Ocean Dyn 65(12):1685-1697

17. Robinson RA, Malanotte-Rizzoli P, Hecht A, Michelato A, Roether W, Theocharis A, Unluata U, Pinardi N, Artegiani A, Bergamasco A, Bishop J, Brenner S, Christianidis S, Gacic M, Georgopoulos D, Golnaraghi M, Hausmann M, Junghaus H-G, Lascaratos A, Latif MA, Leslie WG, Lozano CJ, Oguz T, Ozsoy E, Papageorgiou E, Paschini E, Rozentroub Z, Sansone E, Scarazzato P, Schlitzer R, Spezie GC, Tziperman E, Zodiatis G, Athanassiadou L, Gerges M, Osman M (1992) General circulation of the Eastern Mediterranean. Earth Sci Rev 32:285-309 
18. Schroeder K, Garcia-Lafuente J, Josey SA, Artale V, Nardelli BB, Carrillo A, Gacic M, Gasparini GP, Herrmann M, Lionello P, Ludwig W, Millot C, Özsoy E, Pisacane G, SánchezGarrido JC, Sannino G, Santoleri R, Somot S, Struglia M, Stanev E, Taupier-Letage I, Tsimplis MN, Vargas-Yáñez M, Zervakis V, Zodiatis G (2012) Circulation of the Mediterranean Sea and its variability. In: Lionello P (ed) Climate of the Mediterranean Region. Elsevier, Amsterdam, p 590. https://doi.org/10.1016/B978-0-12-416042-2.00003-3, ISBN: 978-0-12-416042-2, www. sciencedirect.com/science/article/pii/B9780124160422000033

19. Pinardi N, Zavatarelli M, Adani M, Coppini G, Fratianni C, Oddo P, Simoncelli S, Tonani M, Lyubartsev V, Dobricic S, Bonaduce A (2013) Mediterranean Sea large-scale low-frequency ocean variability and water mass formation rates from 1987 to 2007: a retrospective analysis. Prog Oceanogr 132:318. https://doi.org/10.1016/j.pocean.2013.11.003

20. Klemas V (2010) Tracking oil slicks and predicting their trajectories using remote sensors and models: case studies of the sea princess and deepwater horizon oil spills. J Coast Res 26:789-797

21. Liu Y, Weisberg RH, Hu C, Zheng L (2011) Tracking the deepwater horizon oil spill: a modeling perspective. EOS Trans Am Geophys Union 92:45-46. https://doi.org/10.1029/ 2011EO060001

22. Liu Y, MacFadyen A, Ji Z-G, Weisberg RH (eds) (2011) Monitoring and modeling the deepwater horizon oil spill: a record-breaking enterprise. Geophysical monograph series, vol 195. AGU/Geopress, Washington, p 271. ISSN: 0065-8448, ISBN: 978-0-87590-485-6

23. Liu Y, Weisberg RH, Hu C, Zheng L (2011) Trajectory forecast as a rapid response to the deepwater horizon oil spill. Monitoring and modeling the deepwater horizon oil spill: a recordbreaking enterprise. Geophysical Monograph Series, vol 195. American Geophysical Union, Washington, pp 153-165. https://doi.org/10.1029/2011GM001121

24. De Dominicis M, Pinardi N, Zodiatis G, Archetti R (2013) MEDSLIK-II, a Lagrangian marine surface oil spill model for short-term forecasting - Part 2: Numerical simulations and validations. Geosci Model Dev 6:1871-1888. https://doi.org/10.5194/gmd-6-1871-2013

25. Topouzelis KT, Muellenhoff O, Ferraro G, Bulgarelli B (2008) Satellite monitoring of oil spills in the Mediterranean Sea for 1999-2004. In: The 2nd international SAR oceanography workshop, SEASAR 2008 workshop: advances in SAR oceanography from ENVISAT and ERS missions, ESA ESRIN, Frascati, Italy, 21-25 Jan 2008

26. Von Schuckmann K et al (2016) The Copernicus Marine Environment Monitoring Service ocean state report. J Oper Oceanogr 9(sup2):s235-s320. https://doi.org/10.1080/1755876X. 2016.1273446

27. Zodiatis G, De Dominicis M, Perivoliotis L, Radhakrishnan H, Georgoudis E, Sotillo M, Lardner RW, Krokos G, Bruciaferri D, Clementi E, Guarnieri A, Ribotti A, Drago A, Bourma E, Padorno E, Daniel P, Gonzalez G, Chazot C, Gouriou V, Kremer X, Sofianos S, Tintore J, Garreau P, Pinardi N, Coppini G, Lecci R, Pisano A, Sorgente R, Fazioli L, Soloviev D, Stylianou S, Nikolaidis A, Panayidou X, Karaolia A, Gauci A, Marcati A, Caiazzo L, Mancini M (2016) The Mediterranean decision support system for marine safety dedicated to oil slicks predictions. Deep Sea Res II 133:4-20. https://doi.org/10.1016/j.dsr2. 2016.07.014

28. REMPEC (2013) Workshop on regional response capacity and co-ordination for major oil spill in the Mediterranean Sea (MEDEXPOL 2013). www.rempec.org/rempecnews.asp?NewsID=278. Accessed 5 Oct 2017

29. Lardner R, Zodiatis G, Hayes D, Pinardi N (2006) Application of the MEDSLIK oil spill model to the Lebanese spill of July 2006, European Group of Experts on satellite monitoring of sea based oil pollution. European Communities. ISSN: 1018-5593

30. Zodiatis G, Lardner R, Nikolaidis A, Stylianou S, Panayidou X, Hayes D, Galanis G, Georgiou G (2014) MyOcean products in the CYCOFOS and LEV decision support system for marine safety. In: Proceedings of the 6th EuroGOOS international conference: sustainable operational oceanography, EuroGOOS Publication no. 30, pp 290-299. ISBN: 978-91-974828-9-9 
31. Perivoliotis L, Krokos G, Nittis K, Korres G (2011) The Aegean Sea marine security decision support system. Ocean Sci 7:671-683. https://doi.org/10.5194/os-7-671-2011

32. Pollani A, Triantafyllou G, Petihakis G, Nittis K, Dounas K, Koutitas C (2001) The POSEIDON operational tool for the prediction of floating pollutant transport. Mar Pollut Bull 43:270-278. https://doi.org/10.1016/S0025-326X(01)00080-7

33. Perivoliotis L, Nittis K, Korres G (2008) An operational service for oil spill detection and forecasting in the Aegean Sea. In: Abstracts book of the 5th EuroGOOS conference, Exeter, UK, 20-22 May 2008, p 87

34. Papadopoulos A, Kallos G, Katsafados P, Nickovic S (2002) The Poseidon weather forecasting system: an overview. Glob Atmos Ocean Syst 8:219-237

35. Korres G, Papadopoulos A, Katsafados P, Ballas D, Perivoliotis L, Nittis K (2011) A 2yr intercomparison of the WAMCycle4 and the WAVEWATCH-III wave models implemented within the Mediterranean Sea. Mediterr Mar Sci J 12:129-152

36. Lardner R, Zodiatis G, Loizides L, Demetropoulos A (1998) An operational oil spill model for the Levantine Basin (Eastern Mediterranean Sea). In: International symposium on marine pollution, 1998

37. Hasselmann K, Barnett T, Bouws E, Carlson H, Cartwright D, Enke K, Ewing J, Gienapp H, Hasselmann D, Kruseman P, Meerburg A, Mller P, Olbers D, Richter K, Sell W, Walden H (1973) Measurements of wave growth and swell decay during the Joint North Sea Wave Project (JONSWAP). Ergänzungsheft zur Deutschen Hydrographischen ZeitschriftReihe. Deutsches Hydrographisches Institut, Hamburg, pp A8-A12

38. De Dominicis M, Bruciaferri D, Gerin R, Pinardi N, Poulain PM, Garreau P, Zodiatis G, Perivoliotis L, Fazioli L, Sorgente R, Manganiello C (2016) A multi-model assessment of the impact of currents, waves and wind in modeling surface drifters and oil spill. Deep Sea Res II 133:21-38

39. Clementi E, Delrosso D, Pistoia J, Drudi M, Fratianni C, Grandi A, Pinardi N, Oddo P, Tanani M (2016) Mediterranean forecasting system: a focus on wave-current coupling. Geophys Res Abstr 18:EGU2016-EG17275

40. De Dominicis M, Falchetti S, Trotta F, Pinardi N, Giacomelli L, Napolitano E, Fazioli L, Sorgente R, Haley Jr PJ, Lermusiaux PF, Martins F, Cocco M (2014) A relocatable ocean model in support of environmental emergencies. The Costa Concordia emergency case. Ocean Dyn 64:667-688

41. Pinardi N, Coppini G (2010) Preface operational oceanography in the Mediterranean Sea: the second stage of development. Ocean Sci 6:263-267

42. Olita A, Ribotti A, Fazioli L, Perilli A, Sorgente R (2013) Surface circulation and upwelling in the western Sardinia Sea: a numerical study. Cont Shelf Res 71:95-108

43. Vetrano A, Napolitano E, Iacono R, Schroeder K, Gasparini GP (2010) Tyrrhenian Sea circulation and water mass fluxes in spring2004: observations and model results. J Geophys Res Oceans 115(C6):C06023

44. Price JM, Reed M, Howard MK, Johnson WR, Ji ZG, Marshall CF, Guinasso NL, Rainey GB (2006) Preliminary assessment of an oil spill trajectory model using satellite-tracked, oil-spillsimulating drifters. Environ Model Softw 21:258-270

45. Liu Y, Weisberg RH (2011) Evaluation of trajectory modeling in different dynamic regions using normalized cumulative Lagrangian separation. J Geophys Res 116:C09013

46. Samaras AG, De Dominicis M, Archetti R, Lamberti A, Pinardi N (2014) Towards improving the representation of beaching in oil spill models: a case study. Mar Pollut Bull 88:91-101

47. Liubartseva S, De Dominicis M, Oddo P, Coppini G, Pinardi N, Greggio N (2015) Oil spill hazard from dispersal of oil along shipping lanes in the Southern Adriatic and Northern Ionian seas. Mar Pollut Bull 90:259-272

48. Liubartseva S, Coppini G, Pinardi N, De Dominicis M, Lecci R, Turrisi G, Cretì S, Martinelli S, Agostini P, Marra P, Palermo F (2016) Decision support system for emergency management of oil spill accidents in the Mediterranean Sea. Nat Hazards Earth Syst Sci 16:2009-2020 
49. Liubartseva S, Coppini G, Ciliberti SA, Lecci R (2017) Propagation of uncertainties through the oil spill model MEDSLIK-II: operational application to the Black Sea. Geophys Res Abstr 19:EGU2017-EGU4593

50. Price JM, Johnson WR, Marshall CF, Ji Z-G, Rainey GB (2003) Overview of the Oil Spill Risk Analysis (OSRA) model for environmental impact assessment. Spill Sci Technol Bull 8 (5-6):529-533

51. Sepp Neves AA, Pinardi N, Martins F, Janeiro J, Samaras A, Zodiatis G, De Dominicis M (2015) Towards a common oil spill risk assessment framework - adapting ISO 31000 and addressing uncertainties. J Environ Manag 159:158-168

52. Green Line Association (2007) Lebanon oil spill, July 2006-July 2007. Tech. rep., Green Line Association, Beirut Lebanon

53. UNEP - ROWA (2012) Identification and assessment of coastal sensitive areas in Lebanon. Tech. rep., UNEP - Regional Office for West Asia

54. Sepp Neves AA, Pinardi N, Martins F (2016) IT-OSRA: applying ensemble simulations to estimate the oil spill risk associated to operational and accidental oil spills. Ocean Dyn 66:939-954 